\title{
Article \\ On the Part Quality, Process Parameters and In-Die Pressures in Indirect Squeeze Casting
}

\author{
Anders E. W. Jarfors ${ }^{1,2, *} \mathbb{}$, Jie Zhou ${ }^{2}$, Andong Du ${ }^{2,3}$, Jinchuan Zheng ${ }^{2}$ and Gegang $\mathrm{Yu}^{2}$ \\ 1 Materials and Manufacturing, School of Engineering, Jönköping University, P.O. Box 1026, \\ 55111 Jönköping, Sweden \\ 2 Institute of Semi-Solid Metal Technology, China Academy of Machinery Sciences and Technology (Jiangle), \\ No. 22 Huancheng East Road, Jiangle County, Sanming City 353300, China; zhou_j09@163.com (J.Z.); \\ b20170186@xs.ustb.edu.cn (A.D.); $13901302341 @ 139 . c o m$ (J.Z.); yugg@cam.com.cn (G.Y.) \\ 3 Department of Materials Processing and Control Engineering, School of Materials Science and Engineering, \\ University of Science and Technology Beijing, Xueyuan Road No. 30, Haidian District, Beijing 100083, China \\ * Correspondence: anders.jarfors@ju.se
}

check for updates

Citation: Jarfors, A.E.W.; Zhou, J.; Du, A.; Zheng, J.; Yu, G. On the Part Quality, Process Parameters and In-Die Pressures in Indirect Squeeze Casting. Technologies 2021, 9, 95. https://doi.org/10.3390/

technologies 9040095

Academic Editor: Salvatore Brischetto

Received: 29 October 2021

Accepted: 24 November 2021

Published: 2 December 2021

Publisher's Note: MDPI stays neutral with regard to jurisdictional claims in published maps and institutional affiliations.

Copyright: (c) 2021 by the authors. Licensee MDPI, Basel, Switzerland. This article is an open access article distributed under the terms and conditions of the Creative Commons Attribution (CC BY) license (https:// creativecommons.org/licenses/by/ $4.0 /)$.

\begin{abstract}
Squeeze casting is a process that can produce the highest quality castings. In the current study, the effect of the process settings and the in-die conditions on rejection rates is studied through a full-scale experimental study. Factors affecting the as-cast part quality were investigated in the current study from two different viewpoints. The first part of the study was to investigate the influence of the process settings on the part rejection rate, and the second was to understand the conditions in the die and the effects on the part rejection rate to understand better the reasons and sensitivity of the squeeze casting process.
\end{abstract}

Keywords: squeeze casting; process parameters; filling; acceleration; pressure; sensing; rejection rate; aluminium; component casting

\section{Background}

Squeeze casting is a process that can produce the highest quality castings but has a somewhat longer cycle time than other processes such as high pressure die casting (HPDC). The main types are direct squeeze casting and indirect squeeze casting, where the main difference is that for direct squeeze casting, pressure is acting directly on the part, and for indirect squeeze casting, pressure is acting through a runner, but with very little pressure loss compared to HPDC [1,2].

In a recent work by Fiorese et al. [3], the root mean square acceleration significantly impacted the part quality in HPDC. This entity was defined as

$$
\alpha_{R M S}=\frac{1}{T} \int_{0}^{T} \sqrt{\left(\frac{d v}{d t}\right)^{2}} d t
$$

where $v$ is speed $(\mathrm{m} / \mathrm{s}), t$ is time (s) and $T$ is the duration or investigated period(s).

The $\alpha_{R M S}$ value had a direct correlation to the properties, suggesting that the acceleration between the first and the second phase in HPDC determines the quality and not just the actual speed itself. In Fiorese et al. [3] the input was from the piston motion itself, but in reality, the motion of the melt front would be most critical, and a possibility to assess this indirectly would be through die cavity measurements. There is very little work made on squeeze casting regarding filling and product quality which is the focus of this work.

The pressures in the runners and die cavity have a profound impact on casting quality. Recent development in sensor technology increases the possibility of using die sensing technology to understand the filling and solidification dynamics better. In HPDC, the initial peak in heat flux is in the order of $5-10 \mathrm{MW} / \mathrm{m}^{2}$ [4]. and for Squeeze Casting in the order 
of $3 \mathrm{MW} / \mathrm{m}^{2}$ [5]. High initial heat transfer coefficients enable this high heat flux, indicating a high degree of contact between the molten metal. In squeeze casting, the pressure tends to be higher, and the high degree of contact would imply that the main variations in heat transfer coefficient would be due to flow speed, with only a minor variation with pressure. This is also supported by the fact that the variation with the location in the die is strong on both heat transfer and heat flux [4].

The effect of pressure on the heat transfer coefficient can be described as Equation (2) for a system with partial contact and coating/lubrication residues [6]

$$
\frac{1}{h_{\text {tot }}}=R_{\text {tot }}=\left(\frac{R_{\text {air }} R_{\text {contact }}}{R_{\text {air }}+R_{\text {contact }}}\right)+R_{\text {coat }}=a\left(\frac{(b-c \sqrt{P}) \frac{k_{\text {coat }}+k_{\text {cast }}}{k_{\text {coat }} k_{\text {cast }}}}{(b-c \sqrt{P})+a \frac{k_{\text {coat }}+k_{\text {cast }}}{k_{\text {coat }} k_{\text {cast }}}}\right)+\frac{d}{k_{\text {coat }}}
$$

where $h$ is the heat transfer coefficient $\left(W / m^{2} K\right)$ and $R$ is the thermal transport resistance $\left(\mathrm{m}^{2} \mathrm{~K} / \mathrm{W}\right) . h_{\text {tot }}$ is the resulting overall interfacial heat transfer coefficient $\left(\mathrm{W} / \mathrm{m}^{2} \mathrm{~K}\right)$ calculated from the resistance of the air gap resistance $R_{\text {air }}$ and the direct contact resistance $R_{\text {contact }}$. The coating and lubrication residues also influence the Thermal contact resistance as $R_{\text {coat }}$. Furthermore, a is air gap width $(\mathrm{m})$ and $\mathrm{d}$ is coating thickness $(\mathrm{m}) \mathrm{k}$ is thermal conductivity $(\mathrm{W} / \mathrm{mK})$ and $\mathrm{P}$ is pressure $(\mathrm{Pa})$. The to constants $\mathrm{a}, \mathrm{b}$, and c are experimentally determined and depends on materials properties and surfaces roughness. Typical variations would be in the order of $10-20 \%$ for the heat transfer coefficient within the normal pressure ranges.

In an HPDC system, the pressure will vary both with location and with time. The high plunger speeds cause oscillations resulting from hydraulic pressure waves and the dynamics of the metal and filling process. The actual pressure is significantly reduced during filling and solidification with the distance from the plunger dip. Firstly during filling due to the melt viscosity and counter pressure from venting in a high-velocity process as HPDC and secondly during solidification to support the feeding required due to solidification shrinkage [7]. The mechanisms and their relationship in squeeze casting are expected to be significantly different from HPDC, and the relationships with the plunger acceleration identified for HPDC by Fiorese et al. [3] may not be the same.

The oscillations seen in HPDC processing will not be as significant in a squeeze casting process as the injection phase is significantly slower, and pressure waves in the hydraulics will not result in the same type of variations in the filling speed. On the other hand, the filling process during squeeze casting and its consequences for the resulting part quality has not been intensively studied as it has been regarded as a limited problem. In direct squeeze casting, this is fully understandable as the melt is poured directly into the die cavity, and this is a violent process, but pressures from the punch are acting directly into the die cavity, and therefore, the focus has been on the final pressure only [8,9].

The situation is somewhat different for indirect squeeze casting as the melt is supplied from below as an under-up casting process. This should provide the best possible filling conditions. Due to the need to fill the shot sleeve and the need to dock the shot sleeve with the tooling, there is a throat choking the flow into the die cavity that may cause gas entrainment if the first stage of the filling not is well controlled. Indirect die casting also provides the opportunity to increase productivity with a multi-cavity solution adding a runner to the die, making the process similar to HPDC. Speeds are, however, significantly slower $[9,10]$.

Chang et al. [9] studied, in particular, the gating design for indirect squeeze casting with a comparison between a straight gate and a fanned gate. It was concluded that proper gate velocity is required to attain a sound part. If the gate speed is too low, misruns will occur as in conventional casting processes. A rapid filling was also found to break up the stream of metal entering the cavity with entrapped air or gas into the molten metal as a consequence. This resulted in the density of the squeeze castings increasing with lower filling velocities as the effect of the entrapped air could not be fully removed by the final pressure in the squeeze phase. However, the density of the squeeze castings also 
increased with a higher squeezing pressure and above $80 \mathrm{MPa}$ for the A356 alloy, nor further reduction of porosity could be seen.

The rules for process parameter setting for the filling process was investigated by Chang et al. [9] and compared to the gravity casting rules suggested by Campbell [11]. These rules suggest a relationship between the casting geometry and the flow speed and a maximum speed for filling to maintain a stable filling front [11]. Similar suggestions criteria were also developed by Jarfors and Seifeddine [12] based on the Weber number. $\mathrm{Xu}$ and Ying [10] further elaborated this. They used four different types of filling speed selections:

$\mathrm{v}=0.3 \mathrm{~m} / \mathrm{s}$, based on Campbells [11] recommendation, resulting in a calm filling and excessive cooling of the melting front suggesting the formation of defects such as misruns. It should here be noted that the heat transfer coefficient used was $2000 \mathrm{~W} / \mathrm{m}^{2} \mathrm{~K}$ for the simulation, which may be on the low end.

$\mathrm{v}=0.88 \mathrm{~m} / \mathrm{s}$, which is more similar to the upper speed of a squeeze casting machine resulting in jetting in the die cavity and gas entrainment and significant porosity formation. This was also consistent with the work by Chang et al [9].

$\mathrm{v}=0.7 \mathrm{t}^{2}$, where $t$ is time(s) resulting in a very low initial filling speed. This gave a calm filling during the initial filling, but due to the linear acceleration with time, jetting and the unstable filling front was the outcome at a later stage of filling.

$\mathrm{v}=\mathrm{t}$, with constant acceleration, resulted in slow initial filling avoiding gas entrainment and limited jetting at later stages of filling.

The study by $\mathrm{Xu}$ and Ying [10] is valid for one case but demonstrated the need of adapting the flow speed to part geometry while filling in squeeze casting to reach the full potential of the casting process. Like most casting processes Squeeze casting offers a complex difficult to study problem area and regression analuysis and neural networks have been used in an effort to clarify the relationships [13]. Yet, no one has successfully tried to develop a more generic approach such as the approach used by Fiorese et al. [3] for HPDC processing.

In the current study, the effect of the process settings and the in-die conditions on rejection rates is studied through a full-scale experimental study. To understand what makes a good part.

\section{Experimental Work}

\subsection{Material}

The material used in the current study was A356 with its typical specification, as shown in Table 1.

Table 1. Typical composition of the A356 ally used in the current study.

\begin{tabular}{cccccccc}
\hline $\mathbf{S i}$ & $\mathbf{M g}$ & $\mathrm{Fe}$ & $\mathrm{Cu}$ & $\mathrm{Zn}$ & $\mathrm{Mn}$ & $\mathrm{Ti}$ & $\mathrm{Al}$ \\
\hline $6.5-7.5$ & $0.25-0.45$ & 0.2 & 0.2 & 0.2 & 0.1 & 0.1 & $\mathrm{Bal}$ \\
\hline
\end{tabular}

\subsection{Casting Process and Component}

A 650-ton vertical squeeze casting machine was used for the study built by the China Academy of Machinery Sciences and Technology (Jiangle) Institute of Semi-solid Metal Technology.

In all experiments, the casting temperature $\left(653^{\circ} \mathrm{C}\right)$ was kept constant during the investigation to separate only the effects of the filling process.

Pressure sensors were added to the die cavity at three different locations to assess the runner pressure, die cavity pressure and the pressure in one of the overflows as the farthest point away from the point of melt entry. The pressure was also measured at the piston side of the hydraulic system and the return side of the hydraulic pump. In addition, three switch points for filling, feeding and pressure intensification were defined with the standard switch point set as $100 \mathrm{~mm}, 220 \mathrm{~mm}$, and $270 \mathrm{~mm}$ to control the filling speeed. 
The level of $300 \mathrm{~mm}$ for the last pressure intensification phase of the squeeze casting cycle, Figure 1.

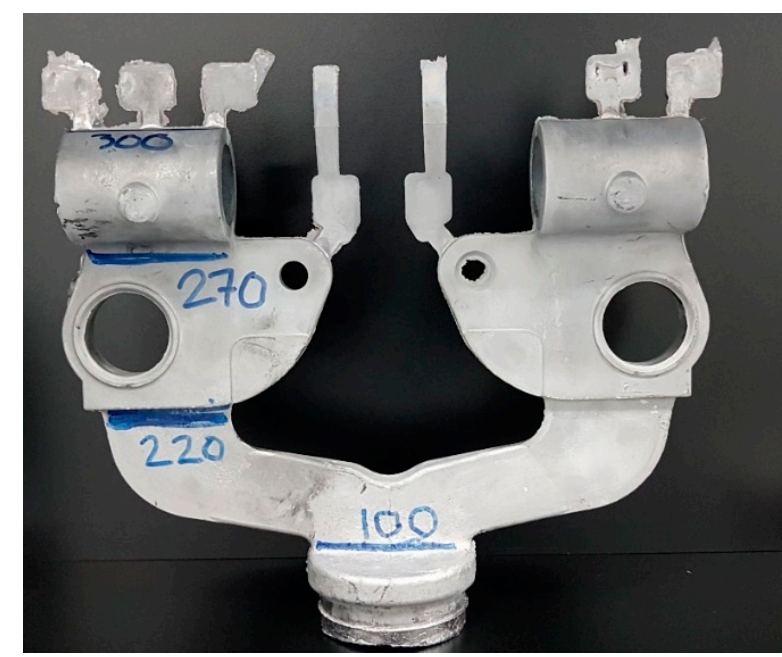

Figure 1. The component cast and the metal levels for the switch points during filling with the numbers indication the piston distance travelled for the melt to reach that level in the die cavity.

\subsection{Characterisation}

To assess the part quality the standard production criteria for a sound product was used and inspected by trained production quality assurance staff. The part quality inspection was made using X-ray analysis (model PW 1729, Philips, Amsterdam, The Netherlands, with $\mathrm{Co}-\mathrm{K} \alpha$ radiation). The exact detection limit was not known for this industrial set-up but the procedure ensured customer acceptance. All defects visible in the X-Ray images lead to rejection which includes porosity and misruns primarily. Occasionally oxides may also be detected in the characterisation process.

\subsection{Experimental Design}

The filling process has been previously optimised, and the component has been in production for some time. The experimental plan is an offset around the ideal conditions, Table 2. During the filling process, several switch points exist, Figure 1. The first switch point is after $100 \mathrm{~mm}$ stroke as the filling meniscus reaches into the runner system. This is a sensitive point due to the resulting geometry originating from the docking of the shot sleeve to the tooling. Dosing of metals have limited accuracy, and disturbances may occur at this point. The first switch point at the melt entry was chosen as one of the parameters to investigate as this also corresponds to the switch between the first and second stage in HPDC studied by Fiorese et al. [3]. Similarly, just as in HPDC, temperature loss in the shot sleeve is significant in squeeze casting. The first phase speed was also chosen as a parameter to study.

Following the finding by $\mathrm{Xu}$ and Ying [10] and accepting that the filling process is at an optimum for the current conditions for the second switch point after a piston movement of $220 \mathrm{~mm}$ and that at $270 \mathrm{~mm}$ were not touched in the current study with $7 \%$ and $13 \%$ speed settings to match the geometrical changes of the cast component. The target is to see how an early disturbance in the filling would affect the process yield and interact with the final intensification pressure. The last switch point takes place after $300 \mathrm{~mm}$, and the typical end of stroke is at $307 \mathrm{~mm}$, at which point the die cavity is fully filled. Here, it is chosen to use the final intensification pressure as the third variable for the study to see how it affects quality after an early disturbance. 
Table 2. Experimental plan and results.

\begin{tabular}{|c|c|c|c|c|c|c|}
\hline Run & $\begin{array}{l}\text { Switch Point } \\
(\mathrm{mm})\end{array}$ & $\begin{array}{l}\text { First Phase } \\
\text { Speed Valve } \\
\text { Setting (\%) }\end{array}$ & $\begin{array}{c}\text { Intensification } \\
\text { Pressure (\%) }\end{array}$ & $\begin{array}{c}\text { Rejection Rate } \\
\text { Left Cavity } \\
\text { (Fraction) }\end{array}$ & $\begin{array}{c}\text { Rejection Rate } \\
\text { Right Cavity } \\
\text { (Fraction) }\end{array}$ & $\begin{array}{l}\text { Total Rejection } \\
\text { Rate (Fraction) }\end{array}$ \\
\hline 1 & 85 & 6 & 50 & 0.7 & 0.5 & 0.6 \\
\hline 2 & 60 & 6 & 24 & 0.4 & 0.3 & 0.35 \\
\hline 3 & 100 & 18 & 50 & 0.3 & 0.2 & 0.25 \\
\hline 4 & 60 & 12 & 22 & 0.1 & 0.1 & 0.1 \\
\hline 5 & 100 & 6 & 10 & 0.3 & 0.3 & 0.3 \\
\hline 6 & 100 & 10 & 33 & 0.8 & 0.4 & 0.6 \\
\hline 7 & 76 & 18 & 33 & 0.6 & 0.1 & 0.35 \\
\hline 8 & 76 & 10 & 10 & 0.6 & 0.1 & 0.35 \\
\hline 9 & 60 & 6 & 50 & 0.5 & 0.3 & 0.4 \\
\hline 10 & 60 & 18 & 10 & 0.3 & 0.3 & 0.3 \\
\hline 11 & 100 & 18 & 10 & 0.2 & 0.1 & 0.15 \\
\hline 12 & 100 & 18 & 50 & 0 & 0 & 0 \\
\hline 13 & 60 & 13 & 50 & 0.4 & 0.2 & 0.3 \\
\hline 14 & 100 & 10 & 33 & 0.8 & 0.2 & 0.5 \\
\hline 15 & 82 & 14 & 50 & 0.2 & 0.2 & 0.2 \\
\hline 16 & 60 & 18 & 10 & 0.8 & 0.2 & 0.5 \\
\hline 18 & 82 & 6 & 23 & 0.3 & 0.4 & 0.35 \\
\hline 19 & 100 & 18 & 10 & 0.4 & 0.4 & 0.4 \\
\hline 20 & 72 & 9 & 37 & 0.2 & 0.4 & 0.3 \\
\hline
\end{tabular}

The optimise and allow for an efficient study, a D-optimal Response Surface Experimental design was used based on the coordinate exchange method and a quadratic model to allow for interactions and non-linear behaviour. The plan includes 5 replicates and 5 lack of fit testing points using the DesignExpert ${ }^{\mathrm{TM}}$ software (StateEase Inc., Minneapolis, MN, USA). The D-Optimal plan is randomised, so there should be no effects of, for instance, a temperature drift in the die caused by a constant increase of the contact pressure and an improved heat transfer to the die. In the performance of the experiments, 10 dummy shots were made to allow for the new conditions to reach a new steady-state before the 10 samples at each setpoint were taken. This means that for the experiments, 200 castings were evaluated out of the 400 castings produced.

\section{Results and Discussion}

\subsection{Characteristic Defects}

The defects encountered are slightly different but easier to detect for lower intensification pressures, as they appear more prominent. The most common defects types and their location are collated in Table 3 . It should be noted that most defects were significantly smaller than the ones illustrated, but the grossest defects are used as they are easier to illustrate.

The first defect illustrated is illustrated by Run 5 and the left cavity. This is in the last region to fill and at an edge. The part is hollow and relatively thin-walled in this region. The defect appears as several C-shaped marks interpreted as laps (a type of cold shut related problem). As the initial speed (B) was low and the switch point high (A), the melt cools more in the shot sleeve and a low temperature most likely aggravated this defect at the end of fills, increasing the risk of cold shuts.

The second defect is illustrated by Run 9 and the left cavity. This is a defect occurring in a thin section just before the entrance to the hollow section. The exact nature of this defect is not clear, but it is either a crack or a cold shot possibly induced by oxides. The setting was such that the initial speed (B) was low, but the end pressure was high. This would make the material coming into the die cooler, and with the high-pressure intensification pressure (C), heat transfer would be high. The region between the two thicker sections to the left and right would solidify significantly later than the thin section resulting in tensile stress in the thin section, with the arrow indicating the principal stress direction and 
crack would be oriented in the $45 \%$ direction to this main stress direction if the material is reasonably ductile. This is also the case for the current defect illustrated.

Table 3. The most common defect and their location, as well as an illustration from interrupted shots. The numbers are the settings for the different runs with A-First phase switch point, B-First phase speed and C-Intensification pressure. The number in the bracket is the range for the setting to gauge if the value is high or low. (Black square is placed due to confidentiality of the product owner).

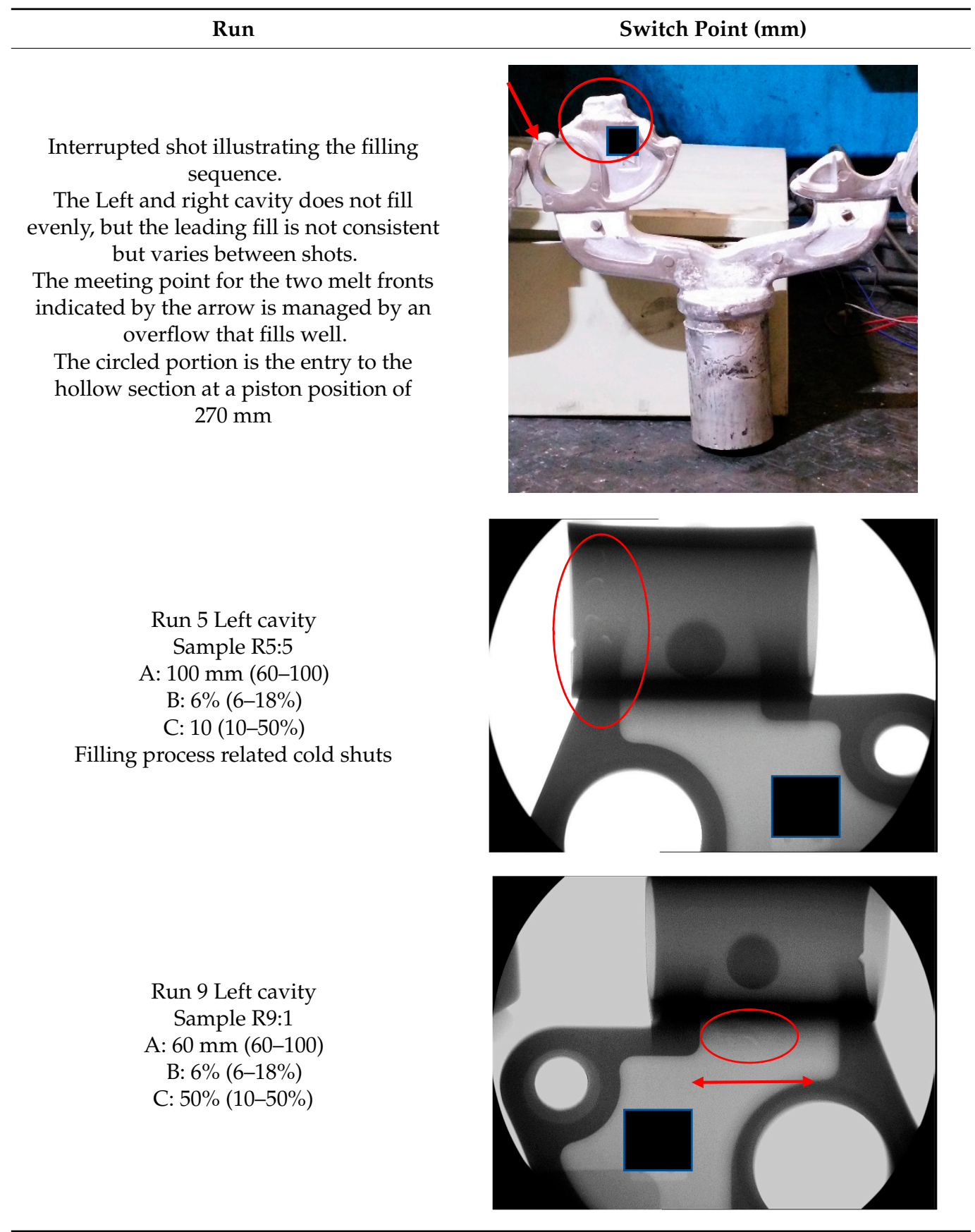


Table 3. Cont.

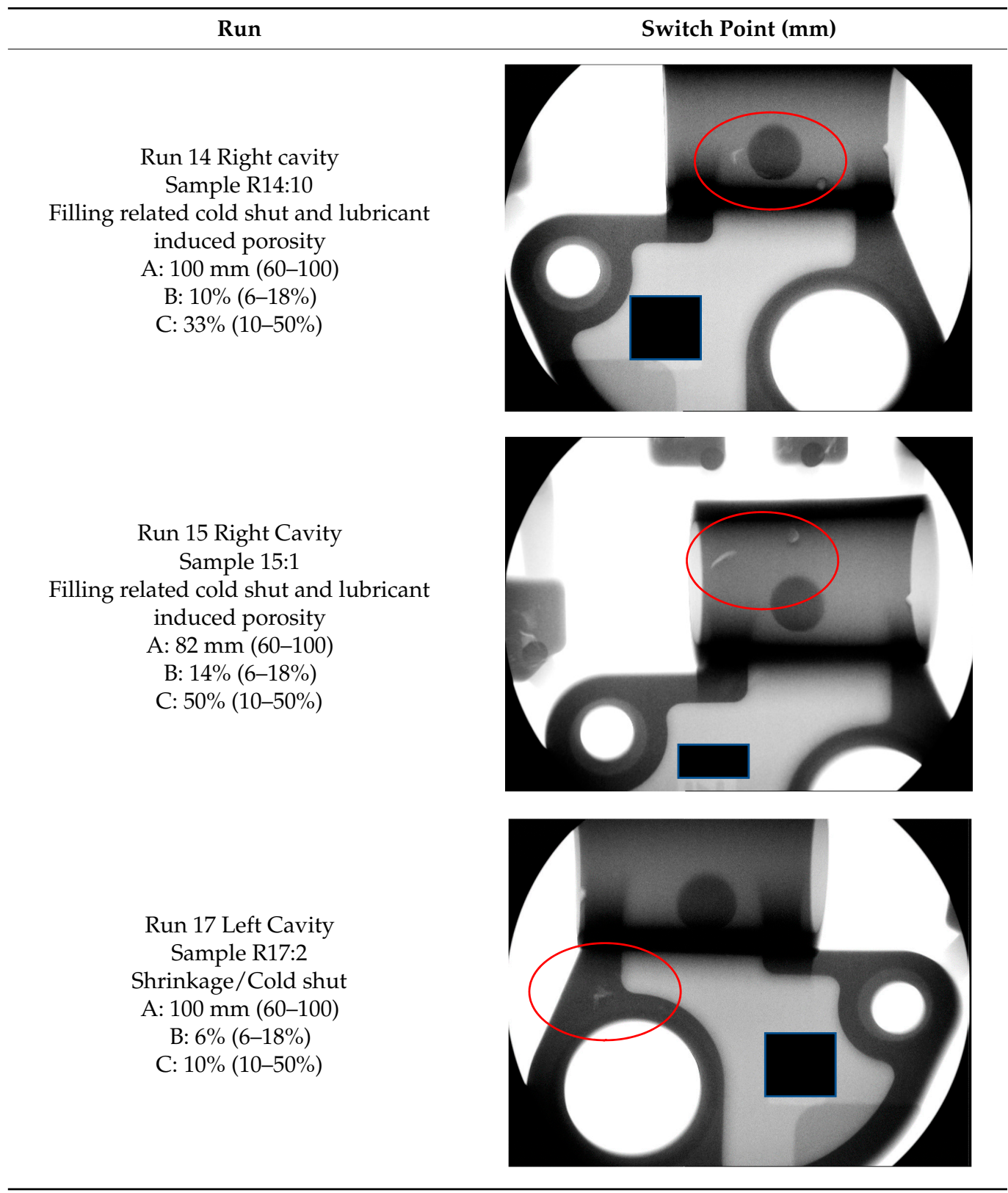

The third defect type is illustrated by Run 14 right cavity and by Run 15 right cavity. This is a combination of two types of defects. The round "bubble" is entrained gas that usually originates from the lubricant spray and other gaseous elements in the die cavity. The main difference between Run 14 and Run 15 is the intensification pressure (C), for which Run 15 is a maximum and Run 14 is in the mid-range. The higher pressure in Run 15 has made the bubble collapse, and it is therefore seen with a weak C-shaped feature but with a similar radius as that found in Run 14, where the pressure was insufficient to compress the entrained gas bobble. The other defect is most likely a cold shut due to premature freezing and the possible presence of oxides.

The fourth and last defect type is illustrated by Run 17 and the left cavity. This is in a region where two melt fronts are meeting as well at a transition between a thick section and a thin section. The fillet radius is large, but this is still a difficult region, especially ad there will be a higher oxide content due to the meeting filling fronts. If the malt comes in cold, then it is difficult for the material to weld together. A lower temperature would also lead to early freezing at the thinner section and make feeding during the intensification process 
more difficult. This problem was aggravated by the setting in Run 17 with a low initial speed (B) and a late switch to higher speed (A), as well as a low intensification pressure (C) not allowing effective feeding of the shrinkage porosity.

\subsection{Process Parameter Setting and Rejection Rates}

The results and the experimental conditions are collated in Table 2. The analysis was made using the built-in Analysis of Variance (ANOVA) in the DesignExpert ${ }^{\mathrm{TM}}$ program. $^{\mathrm{T}}$ The analysis was made on the total rejection rate even though the left cavity performed inferior to the right cavity.

The models were built using a backward principle, starting a quadratic model and reducing the order based on the $p$-value $<0.1$ criteria. This was in some parts of the analysis disregarded as discusses and indicated below.

The ANOVA analysis of the total rejection rate is shown in Table 4 . The Model F-value of 3.63 implies the model is significant. There is only a $2.59 \%$ chance that an F-value this large could occur due to noise. $p$-values less than 0.0500 indicate model terms are significant. Values greater than 0.1000 indicate that the model terms are not significant.

Table 4. ANOVA total rejection rate.

\begin{tabular}{|c|c|c|c|c|c|c|}
\hline Source & $\begin{array}{l}\text { Sum of } \\
\text { Squares }\end{array}$ & df & Mean Square & F-Value & $p$-Value & Comment \\
\hline Model & 0.2716 & 5 & 0.0543 & 3.63 & 0.0259 & Significant \\
\hline A-First phase switch point & 0.0457 & 1 & 0.0457 & 3.05 & 0.1026 & Hierarchy \\
\hline B-First phase speed & 0.0961 & 1 & 0.0961 & 6.41 & 0.0239 & Significant \\
\hline C-Intensification pressure & 0.0053 & 1 & 0.0053 & 0.3538 & 0.5614 & Hierarchy \\
\hline $\mathrm{AB}$ & 0.0820 & 1 & 0.0820 & 5.47 & 0.0347 & Significant \\
\hline BC & 0.1059 & 1 & 0.1059 & 7.07 & 0.0187 & Significant \\
\hline Residual & 0.2097 & 14 & 0.0150 & & & \\
\hline Lack of Fit & 0.0910 & 9 & 0.0101 & 0.4257 & 0.8744 & Not significant \\
\hline Pure Error & 0.1188 & 5 & 0.0238 & & & \\
\hline Cor Total & 0.4814 & 19 & & & & \\
\hline Std. Dev. & 0.1224 & & $\mathrm{R}^{2}$ & 0.5643 & & \\
\hline Mean & 0.3425 & & Adjusted $\mathrm{R}^{2}$ & 0.4087 & & \\
\hline \multirow[t]{2}{*}{ C.V. \% } & 35,74 & & Predicted $\mathrm{R}^{2}$ & 0.0109 & & \\
\hline & & & Adeq Precision & 7.1412 & & \\
\hline
\end{tabular}

The Lack of Fit F-value of 0.43 implies that the Lack of Fit is insignificant relative to the pure error. Non-significant lack of fit is good, as it ascertains that the model fit the results. The Predicted $R^{2}$ of 0,0109 is not as close to the Adjusted $R^{2}$ of 0.4087 as the difference is more than 0.2. It is thus essential to do a complete analysis of the experimental conditions to identify any anomalies and errors that may influence the outcome.

It should be noted that Adeq Precision, which measures the signal to noise ratio is greater than 4 is desirable, was established as 7.141, which indicates an adequate signal. This model can be used to navigate the design space despite that $\mathrm{R}^{2}=0.5643$.

From Table 4, it is seen that A-First phase switch point not is significant as $p>0.05$ but is very close to the limit where it cannot be disregarded $(p<0.1)$. A- First phase switch point was kept to maintain model hierarchy as higher-order terms involving this factor were statistically significant. B-First phase speed, on the other hand, was statistically significant. Interestingly, C-Intensification pressure was not statistically significant, but just as A-First phase switch point was kept keeping model hierarchy intact. The interactions found significant were $\mathrm{AB}$ ( $\mathrm{A}$ - First phase switch point $\mathrm{B}$-First phase speed), indicating that the mode of entry into the runner system is important for the total rejection rate. This suggests that the possibility of jetting and gas entrainment at the docking region and entry into the mould is important, which also agrees with the work by $\mathrm{Xu}$ and Ying [10]. The second interaction found statistically significant was BC (B-First phase speed and CIntensification pressure), suggesting that the mode of runner entry and the intensification 
pressure not is independent, which is similar to the findings by Dargusch et al. [14] for the intensification pressure in HPDC processing.

The resulting model is shown in Equation (1) in actual values. It can be concluded that that the dominating factor was the interaction $\mathrm{BC}$ which is the interaction between B-First phase speed and C-Intensification pressure followed by AB or A-First phase switch point and B-first phase speed. The third and least statistically significant variable was B-First phase speed. In Figure 2a, the rejection rate appears relatively independent on the choice of parameters with a A-First phase switch point set to $60 \mathrm{~mm}$. Increasing this switch point changes the response significantly. Figure $2 \mathrm{~b}$ shows this for the A-First phase switch point set to the maximum value of 100 . Here, the most beneficial setting was the fastest first phase speed combined with the highest intensification pressure.

Rejection rate $=-0.901079+0.013052 A+0.079847 B+0.012399 C-0.000828 A B-0.000942 B C$
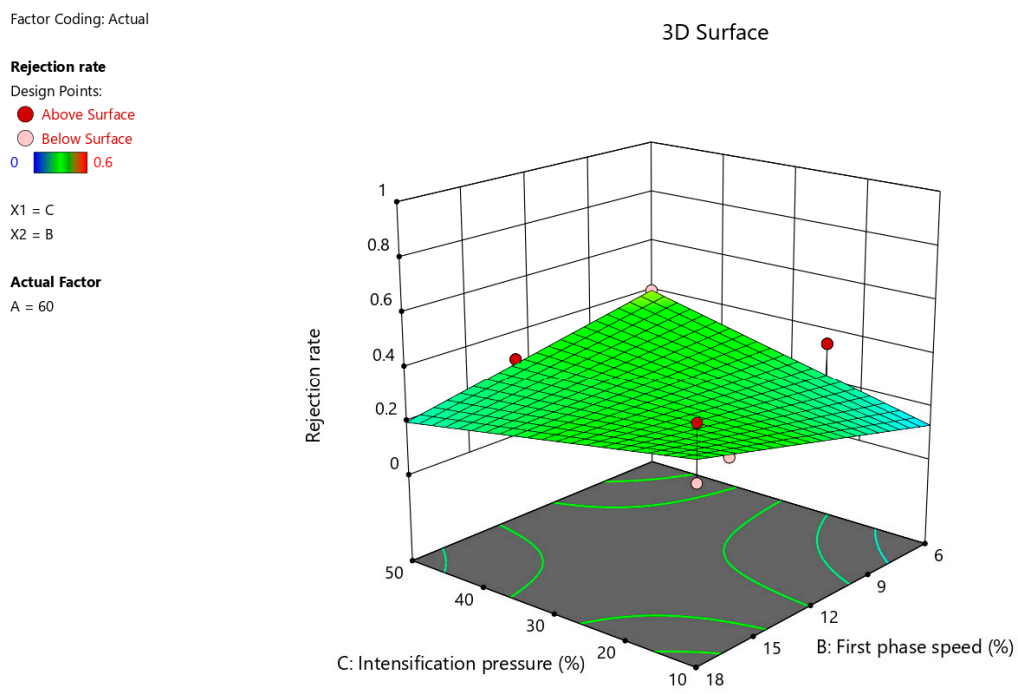

(a)

Factor Coding: Actual

Rejection rate

Design Points:

Above Surface

Below Surface

$\mathrm{X} 1=\mathrm{C}$
$\mathrm{X} 2=\mathrm{B}$

Actual Factor

$A=100$
3D Surface

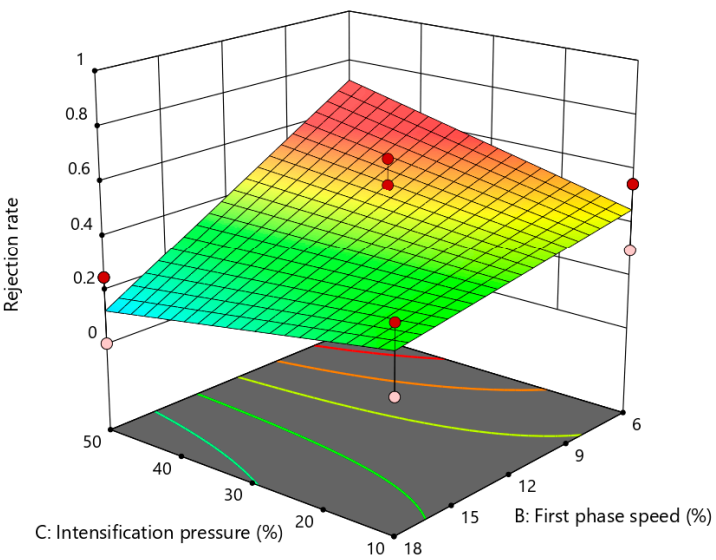

(b)

Figure 2. Model response on total rejection rate (a) A-First phase switch point set to $60 \mathrm{~mm}$ and (b) A-First phase switch point set to $100 \mathrm{~mm}$. 
The fact that the interactions $\mathrm{AB}$ and $\mathrm{BC}$ were significant allows a conclusion that the duration in the shot sleeve is important, meaning that the temperature drop during the first phase has a significant bearing on part quality. The fact that BC is the First phase speed and the Intensification pressure also interact suggests that temperature drop in the sleeve and the defects generated affect the possibility to close these defects during the Intensification phase.

\subsection{Pressure Measurements and Rejection Correlation}

In the current work, two pressures in the hydraulic system were measured (P4 and P5) and three locations in the die with P1 in the runner, P2 in the cavity, and P3 in the overflow. A typical pressure evolution for the sensor locations is shown in Figure 3a.

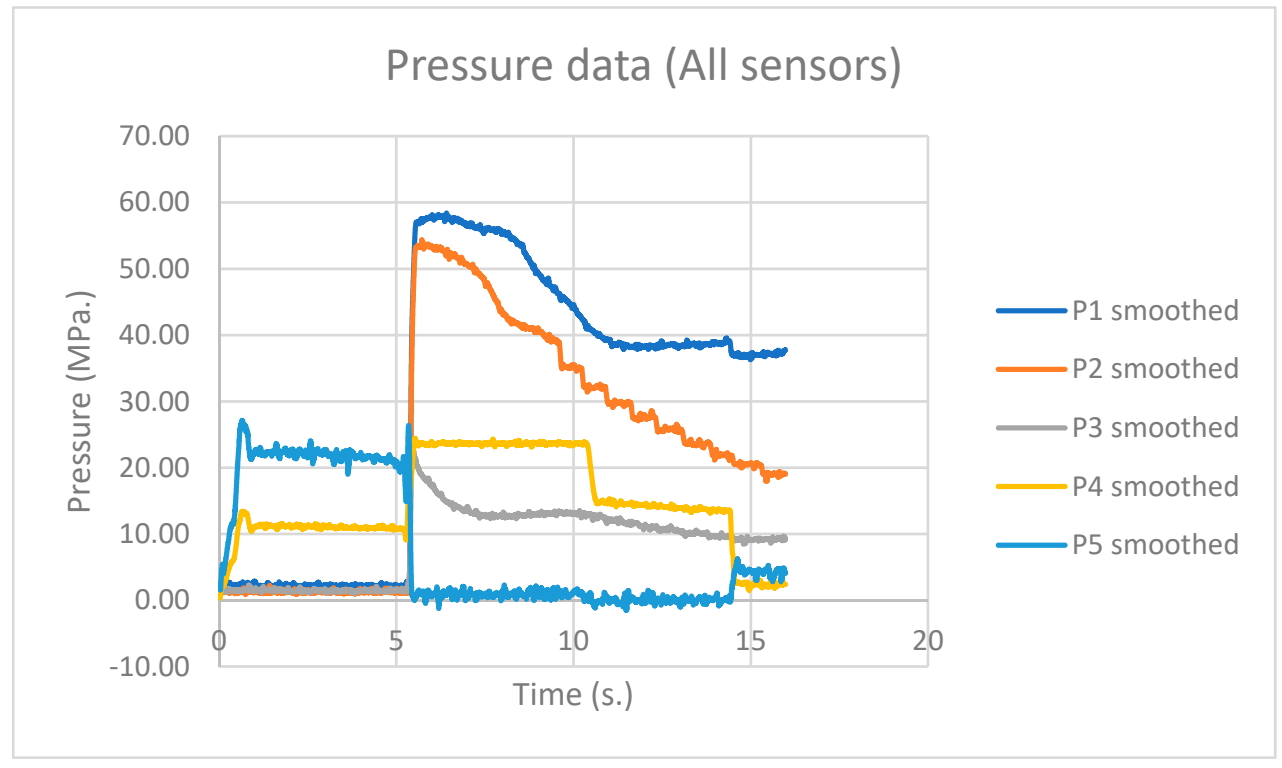

(a)

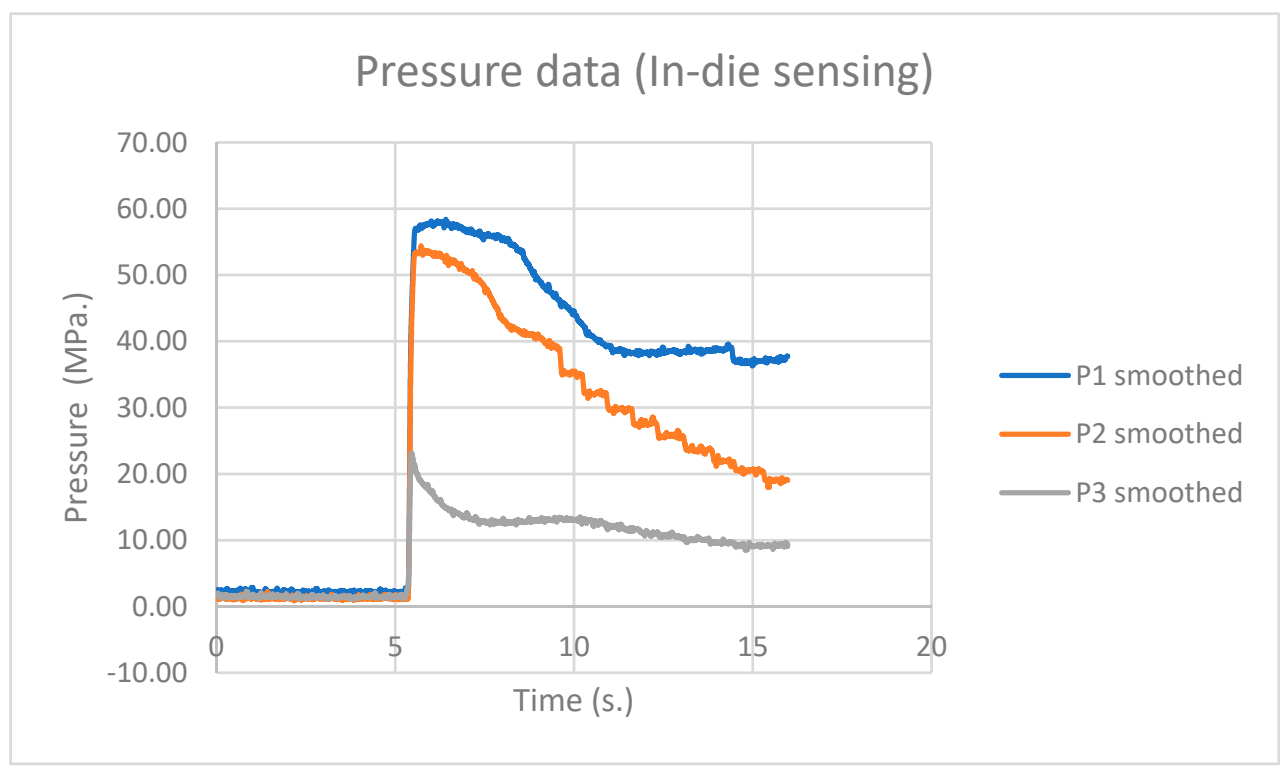

(b)

Figure 3. Cont. 


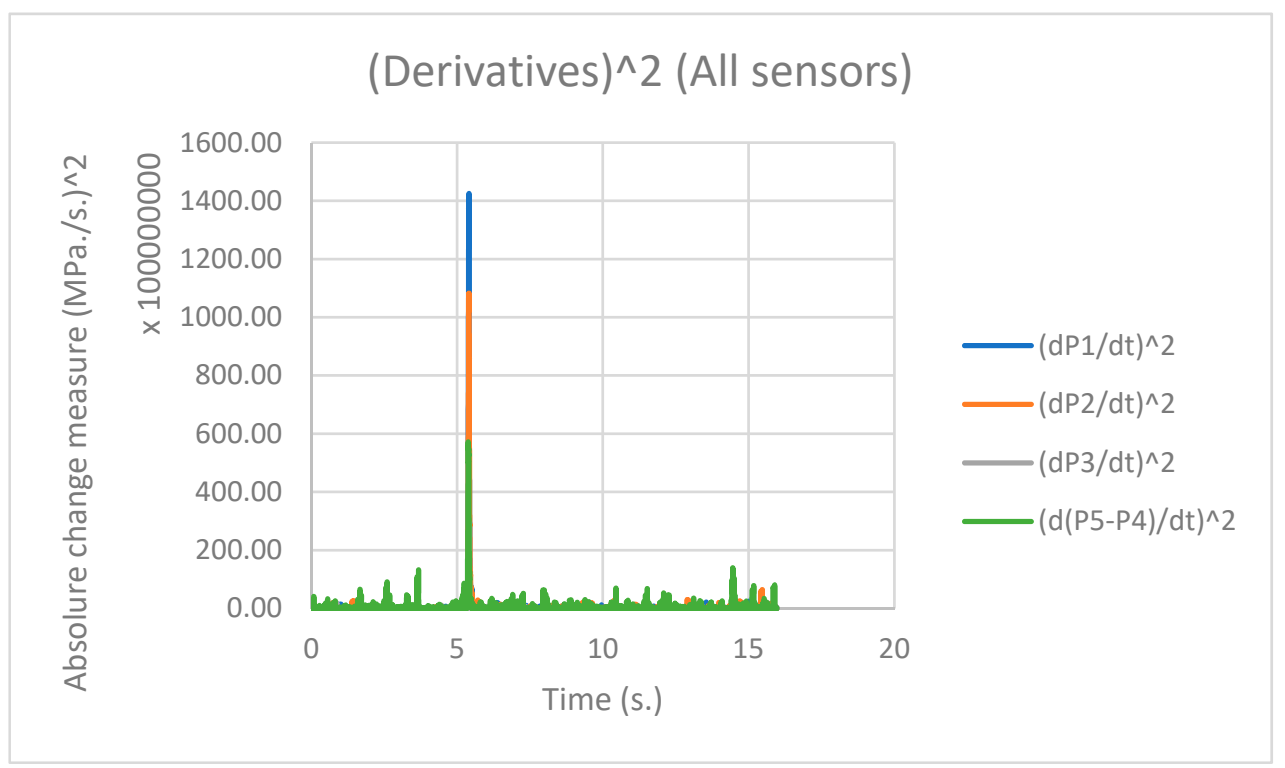

(c)

Figure 3. Measured pressures, an example from Run 4:1 (a) All measured pressure, (b) the in-die pressures alone for clarity, and (c) the squared pressure derivatives.

Based on the work by $\mathrm{Xu}$ and Ying [10] and by Chang et al. [9], it must first be concluded that the final pressure and its application are critical but not independent of the filling process. The turbulence during filling is relatively limited compared to HPDC. Taking this as an approach, a specific analysis of the squeeze casting would rely more on the actual application of pressure.

First, it should be concluded that based on the work by Fiorese et al. [3] the acceleration is given by the driving pressures $P_{4}$ forward acting pressure the poston surface $A_{4}$, and counter acting pressure $P_{5}$ on the opporit surface $A_{5}$, in the piston hydraulics, Equation (4)

$$
P_{4} A_{4}-P_{5} A_{5}=F=m\left(\frac{d v}{d t}\right)
$$

where $m$ is the mass of the piston and the melt in the shot chamber. Applying this directly onto the root mean square criteria developed by Fiorese et al. [3] provided that piston pressure is used.

$$
\alpha_{R M S}=\frac{1}{T} \int_{0}^{T} \sqrt{\left(\frac{d v}{d t}\right)^{2}} d t=\frac{1}{T} \int_{0}^{T} \sqrt{\left(\frac{P_{4} A_{4}-P_{5} A_{5}}{m}\right)^{2}} d t
$$

On the other hand, while filling a cavity, there is a significant pressure drop in the channel, both as it fills up and as it starts to solidify and both apparent viscosity and permeability change with time. Taking the approach of a channel flow for the analysis, the pressure and speed would take a different form and follow a Darcy flow type of relationship with $C_{D A}$ being the permeability factor in Darcy's Law depending on alloy solidification morphology and part geometry leading to that this is unique for each cast part and location in the die cavity [15].

$$
\frac{d P}{d x}=C_{D A} \frac{v}{L}
$$

where $L(\mathrm{~m})$ is the length of the duct of channel. This would lead to a different relationship to the acceleration

$$
\frac{d}{d t}\left(\frac{d P}{d x}\right)=\frac{d}{d t}\left(C_{D A} \frac{v}{L}\right)
$$


The cavity pressure is measure with the outside pressure as a reference taking venting and solidification into account. This would then lead to

$$
\frac{d}{d t}\left(\frac{d P}{d x}\right) \approx \frac{d}{d t}\left(\frac{P_{1,2,3}-P_{a}}{\Delta L_{1,2,3}}\right)=\frac{1}{\Delta L_{1,2,3}} \frac{d P_{1,2,3}}{d t}=\frac{1}{L}\left(\frac{d C_{D A 1,2,3}}{d t} v+C_{D A 1,2,3} \frac{d v}{d t}\right)
$$

The permeability and viscosity, manifested as the perambility coefficient $C_{D A}$ will change significantly during the process and at the different locations indicated as 1,2 , and 3. However, during the transients to be analysed, it is a call change as the duration for the transients are short and therefore is reasonable to neglect this effect in the analysis and development of new pressure-based criteria. The in-cavity pressure changes should be analysed as

$$
\frac{d P_{1,2,3}}{d t}=C \frac{\Delta L_{1,2,3}}{L}\left(\frac{d v}{d t}\right) \equiv C_{D A 1,2,3}\left(\frac{d v}{d t}\right)
$$

This then led to that similar criteria as that derived by Fiorese et al. [3] based on the in-die cavity pressure with the same information content from the die cavity should be written as

$$
\alpha_{R M S}^{P}=\frac{1}{T} \int_{0}^{T} \sqrt{\left(\frac{d P_{1,2,3}}{d t}\right)^{2}} d t
$$

In the analysis of the process parameters, it was shown that there was an influence not only from speeds and switch points but also the intensification pressure. This also implies that accelerations would be of importance and the absolute pressures achieved in the process.

The data from the pressure measurements and the calculated pressure derivatives are collated in Appendix A. A detailed illustration of the pressure evolution in the die cavity is shown in Figure $3 b$ and the derivatives squared in Figure 3c.

Performing the same analysis of the total rejection rate and pressure sensor data for the process parameter settings gives a Model F-value of 62.76 implies the model is significant, Table 5 . There is only a $0.29 \%$ chance that an F-value this large could occur due to noise.

$\mathrm{P}$-values less than 0.0500 indicate model terms are significant. In this case $\mathrm{A}-$ $\left(\mathrm{dP}_{1} / \mathrm{dt}\right)^{2}{ }_{\text {Max }}, \mathrm{B}-\left(\mathrm{dP}_{2} / \mathrm{dt}\right)^{2}{ }_{\text {Max }}, \mathrm{C}-\left(\mathrm{dP}_{3} / \mathrm{dt}\right)^{2}{ }_{\text {Max }}, \mathrm{D}-\mathrm{P}_{1}, \mathrm{E}-\mathrm{P}_{2}, \mathrm{~F}-\mathrm{P}_{3}$ were all statistically significant. It is worthwhile noting that the interactions with the runner pressure were significant in the sense that the runner acceleration interacted, $\mathrm{dP}_{1} / \mathrm{dt}$ with in-die cavity pressure acceleration $\mathrm{dP}_{2} / \mathrm{dt}(\mathrm{AB})$ as well as the acceleration in the overflow $\mathrm{dP}_{3} / \mathrm{dt}(\mathrm{AC})$ the maximum pressure in the runner (AD). There was also an interaction between the actual pressures in the die cavity $\mathrm{P}_{2}$ and in the overflow $\mathrm{P}_{3}(\mathrm{EF})$. Values greater than 0.1000 indicate the model terms are not significant.

The Predicted $\mathrm{R}^{2}$ of 0.8393 is in reasonable agreement with the Adjusted $\mathrm{R}^{2}$ of 0,9794 ; i.e., the difference is less than 0.2. Furthermore, Adeq Precision measures the signal to noise ratio. A ratio greater than 4 is desirable, and a ratio of 26.846 was achieved, and an adequate signal to noise ratio was achieved. This model can be used to navigate the design space. Compared to the process settings, the outcome results in a more significant en better fitting model by comparison in terms of $R^{2}$ and the similarity in the Adjusted $R^{2}$ and Predicted $\mathrm{R}^{2}$.

The regression equation in terms of actual factors is shown in Equation (11).

$$
\begin{aligned}
\text { Rejection rate }= & -2.82260-1.17603 \times 10^{-12} A+1.10466 \times 10^{-10} B \\
& -7.13225 \times 10^{-11} C+0.018487 D+0.059012 E+0.343578 F \\
& -1.32054 \times 10^{-21} A B+7.92514 \times 10^{-22} A C-3.39224 \times 10^{-13} A D \\
& -0.006283 E F
\end{aligned}
$$


Table 5. ANOVA total rejection rate and in-die sensing analysis.

\begin{tabular}{ccccccc}
\hline Source & Sum of Squares & df & Mean Square & F-Value & $p$-Value & Comment \\
\hline Model & 0.2895 & 10 & 0.0290 & 62.76 & 0.0029 & Significant \\
A-(dP1/dt)2Max & 0.0663 & 1 & 0.0663 & 143.62 & 0.0012 & Significant \\
B-(dP2/dt)2Max & 0.0278 & 1 & 0.0278 & 60.22 & 0.0045 & Significant \\
C-(dP3/dt)2Max & 0.0182 & 1 & 0.0182 & 39.47 & 0.0081 & Significant \\
D-P1 & 0.0077 & 1 & 0.0077 & 16.72 & 0.0264 & Significant \\
E-P2 & 0.0856 & 1 & 0.0856 & 185.45 & 0.0009 & Significant \\
F-P3 & 0.0675 & 1 & 0.0675 & 146.40 & 0.0012 & Significant \\
AB & 0.1042 & 1 & 0.1042 & 225.88 & 0.0006 & Significant \\
AC & 0.0942 & 1 & 0.0942 & 204.28 & 0.0007 & Significant \\
AD & 0.0149 & 1 & 0.0149 & 32.23 & 0.0108 & Significant \\
EF & 0.0486 & 1 & 0.0486 & 105.39 & 0.0020 & Significant \\
Residual & 0.0014 & 3 & 0.0005 & 62.76 & 0.0029 & 0.0012 \\
Cor Total & 0.2909 & 13 & 0.0290 & 143.62 & & \\
Std. Dev. & 0.0215 & & R & & \\
Mean & 0.3393 & & Adjusted R & 0.9952 & & \\
C.V. $\%$ & 6.33 & & Predicted R & 0.8393 & & \\
& & Adeq Precision & 26.8460 & & \\
\hline
\end{tabular}

The runs that were ignored due to outliers in this analysis were: $9,12,15,16,17,18$.

Analysing the output, it becomes clear that there are rather sharp boundaries between regions with low rejection rates and regions with high rejection rates, suggesting that there are critical limits or thresholds in terms of accelerations and pressures to produce a sound part, Figure $4 \mathrm{a}-\mathrm{d}$.

The acceleration in the runner and the part (A-B relationship) suggested that both could be small or high, Figure $4 \mathrm{a}$. Deviations where one acceleration is mismatched with the other resulted in rejection. The pressure difference between the two points represents the driving force of filling. Since the system is a two-cavity system and pressure were measured in one cavity, the mismatch in acceleration would then suggest an uneven filling between the cavities, as seen in the interrupted shot Table 2.

The acceleration in the runner and the overflow showed a different relationship where the most advantageous combination was a reversed relationship compared to the runner and cavity acceleration. The lowest rejections were found with combinations with ha high runner acceleration and a low acceleration in the overflow and vice versa, Figure $4 \mathrm{~b}$. This relationship requires further investigations to be fully clarified.

The interaction between pressure acceleration in the runner and maximum pressure in the runner shows a matching relationship with higher acceleration and higher final pressures producing sound parts, Figure 3c. It should be noted that this is not the same relationship that was seen in the process control settings where a higher first stage speed reduced the rejection rate. The effect from a slow first stage fill will eventually generate externally solidified crystals that commonly lead to defects. This effect is not included in the acceleration analysis as the high acceleration levels are only seen at the switch point from the first to the second stage in the casting process, Figure 3c. Figure 3c suggests a minimum acceleration is required for a good part, and this acceleration limit is reduced by using a higher final pressure in the part cavity.

The relationship between the cavity and the overflow is difficult, but the hight both gets, the more stable the process becomes, and this supports the common idea used in squeeze casting that the higher the end pressure, the better the part. 
Factor Coding: Actual

Rejection rate

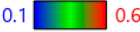

$\mathrm{X} 1=\mathrm{A}$

$\mathrm{X} 2=\mathrm{B}$

Actual Factors

$C=8.63635 \mathrm{E}+10$

$D=34.74$

$E=36.68$

$\mathrm{F}=20.775$

Factor Coding: Actual

$$
\begin{aligned}
& \text { Rejection rate } \\
& 0.1 \\
& X 1=A \\
& X 2=C \\
& \text { Actual Factors } \\
& B=4.91915 E+10 \\
& D=34.74 \\
& E=36.68 \\
& F=20.775
\end{aligned}
$$

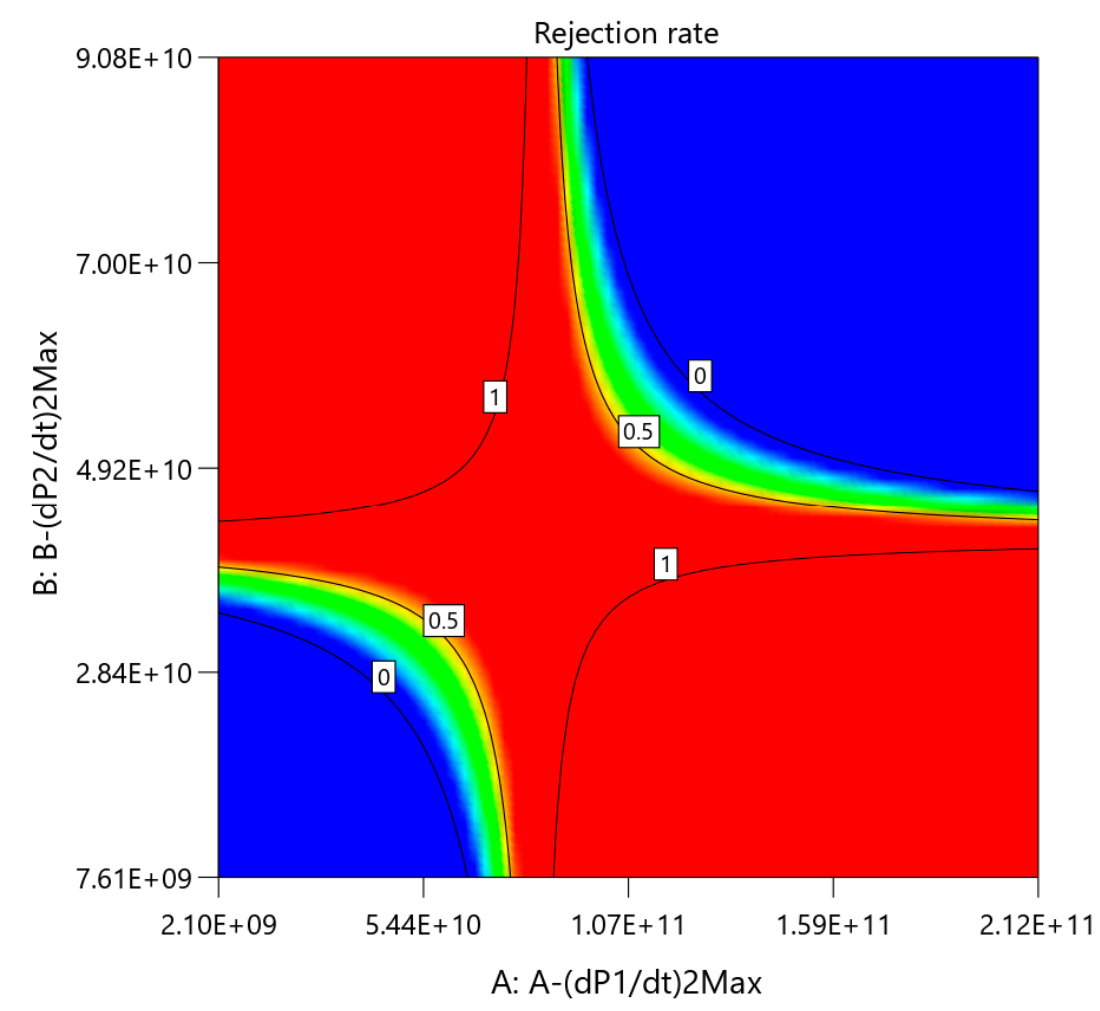

(a)

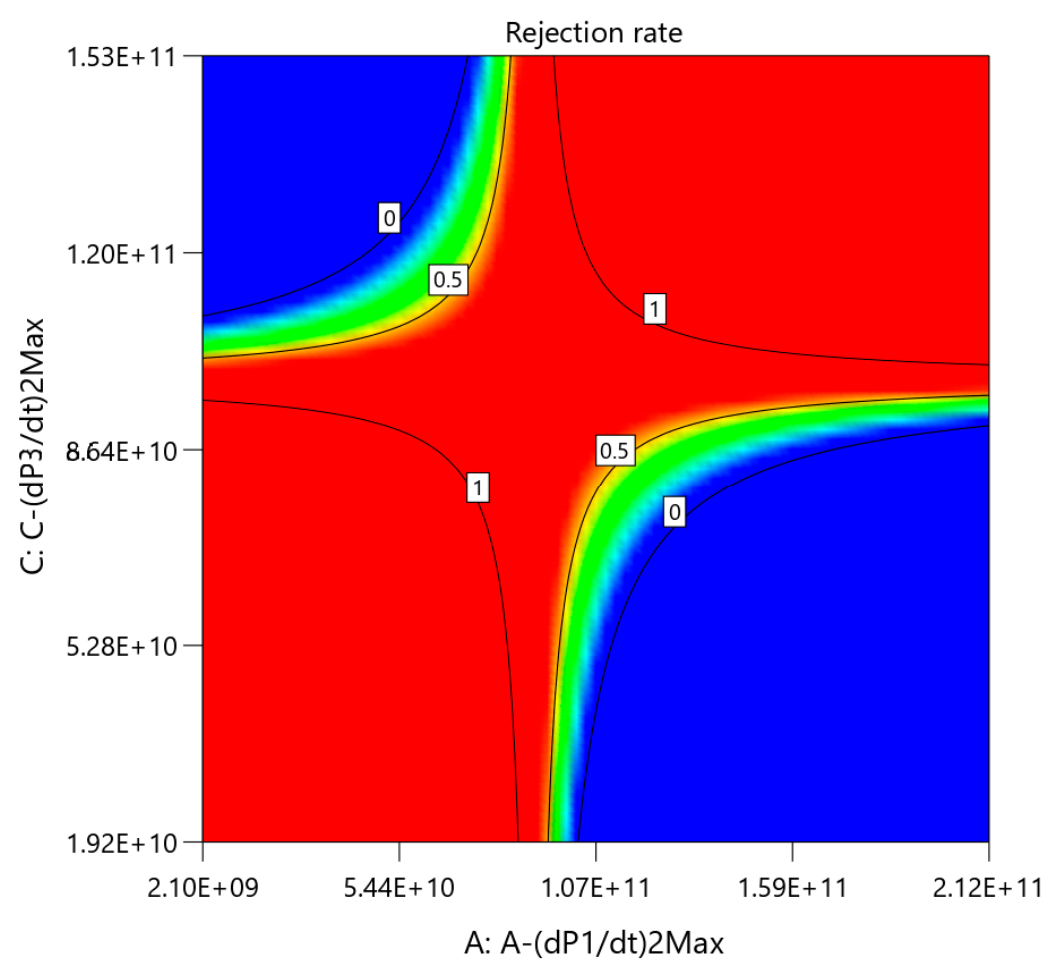

(b)

Figure 4. Cont. 


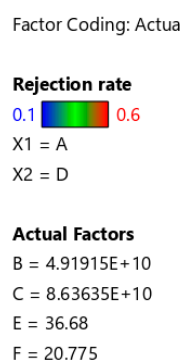

Factor Coding: Actual

$$
\begin{aligned}
& \text { Rejection rate } \\
& \begin{array}{l}
0.1 \\
\mathrm{X} 1=\mathrm{E} \\
\mathrm{X} 2=\mathrm{F}
\end{array} \\
& \text { Actual Factors } \\
& \mathrm{A}=1.06798 \mathrm{E}+11 \\
& \mathrm{~B}=4.91915 \mathrm{E}+10 \\
& \mathrm{C}=8.63635 \mathrm{E}+10 \\
& \mathrm{D}=34.74
\end{aligned}
$$

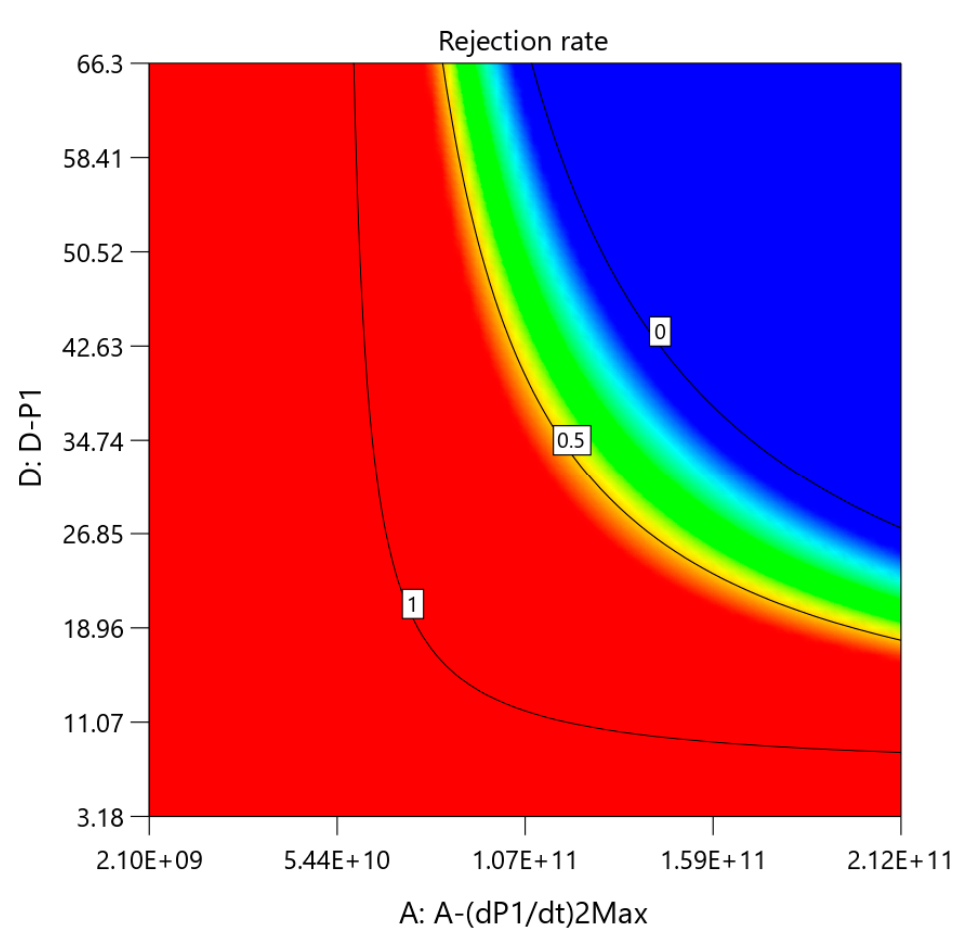

(c)

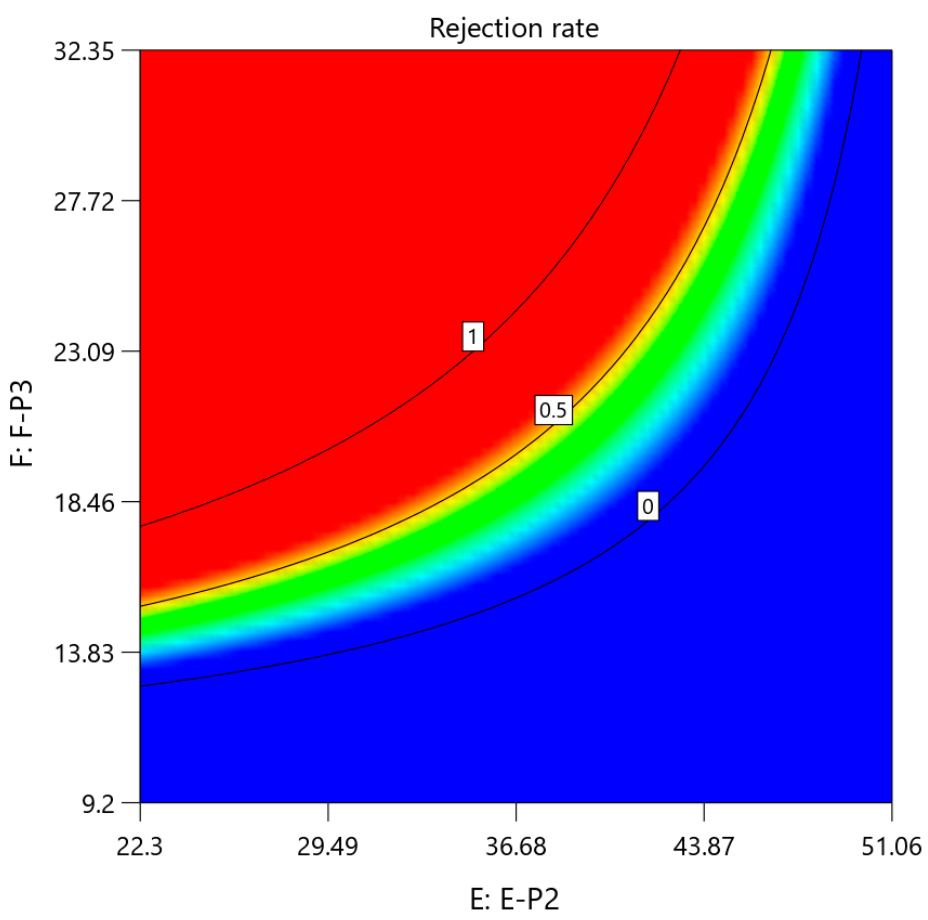

(d)

Figure 4. Discovered relationships between the process parameters and the resulting rejection rate (Blue is all pass and

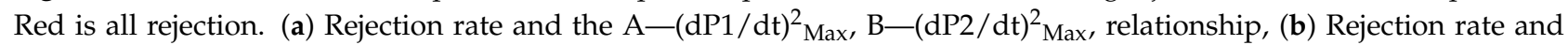
the $\mathrm{A}-(\mathrm{dP} 1 / \mathrm{dt})^{2}{ }_{\text {Max }}, \mathrm{C}-(\mathrm{dP} 3 / \mathrm{dt})^{2}{ }_{\text {Max }}$ relationship, (c) Rejection rate and the $\mathrm{A}-(\mathrm{dP} 1 / \mathrm{dt})^{2}{ }_{\text {Max }}, \mathrm{D}-\mathrm{P}_{1}$ relationship and (d) Rejection rate and $\mathrm{E}-\mathrm{P}_{2}, \mathrm{~F}-\mathrm{P}_{3}$ relationship. 


\section{Conclusions}

Factors affecting the as-cast part quality were investigated in the current study from two different viewpoints. The first part of the study was to investigate the influence of the process settings on the part rejection rate, and the second was to understand the conditions in the die and the effects on the part rejection rate to understand better the reasons and sensitivity of the squeeze casting process.

For the overall performance of the squeeze casting process, the influence of the process parameters settings, it was found that the interactions between A-First phase switch point and B-First phase speed were significant both statistically and physically. An early switch point $(60 \mathrm{~mm})$ made the rejection rate more insensitive to the other process parameters. A late switch point decreased the rejection rate with a higher first stage speed and a higher intensification pressure. On the other hand, a slower fist phase speed and a high intensification pressure resulted in a high rejection rate. This indicates that the duration of the melt in the shot sleeve and the runner is critical to part quality and most likely cause a temperature drop with the formation of cold shuts and folds that cannot be closed by a high intensification pressure. This was also supported by the interaction between B-First phase speed and C-Intensification pressure, where low speed and low intensification pressures increase the rejection rate.

The process parameter setting provides a basic idea about the control of the process. Based on the analysis by Fiorese et al. [3] a new factor to assess quality was derived, allowing a similar root mean square measure of acceleration to be used together with pressure sensing in the process instead. Using this acceleration measure and the maximum pressures, a model for the rejection rates was built. This approach allowed for an improved definition of good and bad conditions in the die. The following conclusions could be made

- Runner and part cavity rate of pressure increase need to be matched, either low or high. Mismatching may be due to waves or uneven cavity fill in a multi-cavity die.

- Just as for the runner and die cavity pressures, there is a similar relationship between the die cavity and the overflow pressure. If the overflow pressure gets too close to the part cavity, pressure rejection rates are increased. This supports that a smooth filling is required, and the minimum difference in the current case was $10 \mathrm{MPa}$.

- The overflow location rate of pressure increase should not be matched with the runner pressure increase. The cause of this is difficult to understand and requires further investigation.

- The decoupling of the overflow makes a single point measurement in the overflow difficult to use as a quality measure whist a two-point measurement un the runner and in the cavity show a logical correlation as they needed matching. Matching means that the difference in pressure between the runner and part cavity that drives filling is better suited as a quality measure.

- The runner conditions themselves could also be important as a quality measure as there is a relationship indicating that a higher acceleration and a higher final pressure in the die cavity would promote a lower rejection rate. This relationship is likely coupled to the contact time for the melt in the shot sleeve and the associated temperature drop.

Author Contributions: Conceptualisation, A.E.W.J. and J.Z. (Jinchuan Zheng); methodology, A.E.W.J. and J.Z. (Jie Zhou); investigation, J.Z. (Jie Zhou) and A.D.; resources, J.Z. (Jinchuan Zheng) and G.Y.; writing — original draft preparation, A.E.W.J.; writing — review and editing, all authors together; project administration, J.Z. (Jinchuan Zheng) and G.Y.; funding acquisition, J.Z. (Jinchuan Zheng) and G.Y. All authors have read and agreed to the published version of the manuscript.

Funding: This research was funded by the 1000 Foreign Talent Programme, China and from Knowledge Foundation under the Compcast Plus project (Dnr. 20170066).

Institutional Review Board Statement: Not Applicable.

Informed Consent Statement: Not Applicable. 
Data Availability Statement: The data used is collated in Appendix A.

Acknowledgments: The authors are indebted to the staff at China Academy of Machinery Sciences and Technology (Jiangle) Institute of Semi-Solid Metal Technology. A special thank you to Chen Qiurong for the kind support, translations and help.

Conflicts of Interest: The authors declare no conflict of interest, and the funders had no role in the design of the study, in the collection, analyses, or interpretation of data, in the writing of the manuscript, or in the decision to publish the results.

\section{Appendix A}

In Appendix A all data from the individual runs are collated in Table 1.

Table 1. The data used in the analysis.

\begin{tabular}{|c|c|c|c|c|c|c|c|c|c|}
\hline Run & $(\mathrm{dP1} / \mathrm{dt})^{2}{ }_{\mathrm{Max}}$ & $(\mathrm{dP} 2 / \mathrm{dt})^{2}$ Max & $(\mathrm{dP} 3 / \mathrm{dt})^{2}$ Max & $\mathbf{P} 1_{\max }$ & $\mathbf{P} 2_{\max }$ & $\mathbf{P} 3_{\max }$ & Left Reject & $\begin{array}{l}\text { Right } \\
\text { Reject }\end{array}$ & $\begin{array}{c}\text { Total } \\
\text { Reject }\end{array}$ \\
\hline $1-1$ & $7.68 \times 10^{10}$ & $7.32 \times 10^{10}$ & $1.02 \times 10^{11}$ & 35.99 & 42.36 & 27.61 & 1 & 0 & 1 \\
\hline $1-2$ & $8.31 \times 10^{10}$ & $2.59 \times 10^{10}$ & $5.99 \times 10^{10}$ & 40.66 & 36.83 & 21.55 & 1 & 1 & 2 \\
\hline $1-3$ & $3.97 \times 10^{10}$ & $1.54 \times 10^{10}$ & $6.26 \times 10^{10}$ & 46.58 & 44.65 & 16.37 & 0 & 1 & 1 \\
\hline $1-4$ & $1.13 \times 10^{11}$ & $3.28 \times 10^{10}$ & $9.59 \times 10^{10}$ & 42.10 & 42.16 & 23.53 & 1 & 1 & 2 \\
\hline $1-5$ & $3.97 \times 10^{10}$ & $1.54 \times 10^{10}$ & $6.26 \times 10^{10}$ & 46.58 & 44.65 & 16.37 & 1 & 0 & 1 \\
\hline $1-6$ & $7.36 \times 10^{10}$ & $5.94 \times 10^{09}$ & $6.00 \times 10^{10}$ & 32.87 & 37.27 & 8.07 & 0 & 0 & 0 \\
\hline $1-7$ & $1.05 \times 10^{11}$ & $4.57 \times 10^{10}$ & $7.26 \times 10^{10}$ & 41.07 & 40.10 & 23.18 & 1 & 1 & 2 \\
\hline $1-8$ & $6.50 \times 10^{10}$ & $4.60 \times 10^{10}$ & $4.55 \times 10^{10}$ & 33.35 & 33.02 & 27.14 & 1 & 0 & 1 \\
\hline $1-9$ & $1.18 \times 10^{11}$ & $2.17 \times 10^{10}$ & $9.36 \times 10^{10}$ & 45.28 & 38.87 & 19.46 & 1 & 1 & 2 \\
\hline $1-10$ & $1.44 \times 10^{11}$ & $8.65 \times 10^{10}$ & $1.28 \times 10^{11}$ & 49.61 & 44.16 & 32.18 & 0 & 0 & 0 \\
\hline $2-1$ & $4.34 \times 10^{10}$ & $1.17 \times 10^{10}$ & $2.22 \times 10^{10}$ & 34.08 & 32.19 & 15.88 & 0 & 1 & 1 \\
\hline $2-2$ & $2.98 \times 10^{10}$ & $4.42 \times 10^{09}$ & $9.50 \times 10^{09}$ & 30.97 & 21.98 & 10.69 & 1 & 0 & 1 \\
\hline $2-3$ & $9.57 \times 10^{10}$ & $2.58 \times 10^{10}$ & $7.42 \times 10^{10}$ & 41.64 & 42.72 & 20.94 & 0 & 0 & 0 \\
\hline $2-4$ & $1.04 \times 10^{11}$ & $4.00 \times 10^{10}$ & $5.55 \times 10^{10}$ & 47.77 & 44.03 & 20.61 & 1 & 1 & 2 \\
\hline $2-5$ & $9.70 \times 10^{10}$ & $1.86 \times 10^{10}$ & $5.41 \times 10^{10}$ & 56.33 & 55.58 & 27.61 & 0 & 0 & 0 \\
\hline $2-6$ & $7.25 \times 10^{10}$ & $9.33 \times 10^{09}$ & $4.33 \times 10^{10}$ & 51.23 & 50.04 & 16.16 & 0 & 0 & 0 \\
\hline $2-7$ & $1.37 \times 10^{11}$ & $2.94 \times 10^{10}$ & $1.06 \times 10^{11}$ & 53.34 & 46.17 & $27 .^{11}$ & 0 & 0 & 0 \\
\hline $2-8$ & $1.35 \times 10^{11}$ & $3.37 \times 10^{10}$ & $7.42 \times 10^{10}$ & 55.93 & 43.47 & 24.89 & 0 & 1 & 1 \\
\hline $2-9$ & $1.27 \times 10^{11}$ & $2.69 \times 10^{10}$ & $1.20 \times 10^{11}$ & 52.99 & 51.14 & 21.26 & 1 & 0 & 1 \\
\hline $2-10$ & $1.29 \times 10^{11}$ & $6.11 \times 10^{10}$ & $8.28 \times 10^{10}$ & 55.62 & 43.10 & 28.13 & 1 & 0 & 1 \\
\hline $3-1$ & $6.94 \times 10^{10}$ & $6.70 \times 10^{10}$ & $2.84 \times 10^{10}$ & 36.84 & 29.34 & 27.29 & 0 & 1 & 1 \\
\hline $3-2$ & $8.74 \times 10^{10}$ & $7.46 \times 10^{10}$ & $7.22 \times 10^{10}$ & 39.24 & 40.24 & 31.00 & 0 & 0 & 0 \\
\hline $3-3$ & $1.11 \times 10^{11}$ & $1.07 \times 10^{11}$ & $7.00 \times 10^{10}$ & 43.57 & 40.29 & 35.49 & 0 & 1 & 1 \\
\hline $3-4$ & $1.08 \times 10^{11}$ & $2.30 \times 10^{10}$ & $8.70 \times 10^{10}$ & 42.37 & 40.65 & 22.13 & 1 & 0 & 1 \\
\hline $3-5$ & $1.29 \times 10^{11}$ & $3.69 \times 10^{10}$ & $1.17 \times 10^{11}$ & 49.26 & 44.68 & 24.21 & 0 & 0 & 0 \\
\hline $3-6$ & $1.33 \times 10^{11}$ & $3.08 \times 10^{10}$ & $1.04 \times 10^{11}$ & 49.36 & 44.76 & 24.30 & 0 & 0 & 0 \\
\hline $3-7$ & $1.44 \times 10^{11}$ & $3.09 \times 10^{10}$ & $1.21 \times 10^{11}$ & 54.79 & 53.13 & 24.64 & 0 & 0 & 0 \\
\hline $3-8$ & $1.60 \times 10^{11}$ & $3.87 \times 10^{10}$ & $1.26 \times 10^{11}$ & 52.81 & 48.85 & 22.54 & 1 & 0 & 1 \\
\hline $3-9$ & $1.67 \times 10^{11}$ & $5.04 \times 10^{10}$ & $1.33 \times 10^{11}$ & 57.65 & 46.00 & 25.34 & 1 & 0 & 1 \\
\hline $3-10$ & $1.27 \times 10^{11}$ & $2.92 \times 10^{10}$ & $8.22 \times 10^{10}$ & 56.39 & 47.82 & 26.93 & 0 & 0 & 0 \\
\hline $4-1$ & $1.43 \times 10^{11}$ & $2.95 \times 10^{10}$ & $1.08 \times 10^{11}$ & 58.41 & 54.41 & 23.16 & 0 & 0 & 0 \\
\hline $4-2$ & $1.26 \times 10^{11}$ & $3.03 \times 10^{10}$ & $9.46 \times 10^{10}$ & 53.07 & 51.91 & 26.69 & 0 & 0 & 0 \\
\hline $4-3$ & $1.17 \times 10^{11}$ & $4.80 \times 10^{10}$ & $8.92 \times 10^{10}$ & 50.85 & 49.83 & 30.83 & 0 & 0 & 0 \\
\hline $4-4$ & $1.09 \times 10^{11}$ & $2.22 \times 10^{10}$ & $6.41 \times 10^{10}$ & 51.16 & 49.54 & 32.03 & 0 & 0 & 0 \\
\hline $4-5$ & $1.41 \times 10^{11}$ & $3.17 \times 10^{10}$ & $8.96 \times 10^{10}$ & 57.78 & 47.22 & 23.04 & 0 & 0 & 0 \\
\hline $4-6$ & $7.46 \times 10^{10}$ & $1.61 \times 10^{10}$ & $5.00 \times 10^{10}$ & 59.94 & 54.08 & 25.20 & 0 & 0 & 0 \\
\hline $4-7$ & $1.50 \times 10^{11}$ & $2.71 \times 10^{10}$ & $9.48 \times 10^{10}$ & 56.27 & 49.53 & 21.58 & 0 & 1 & 1 \\
\hline $4-8$ & $1.44 \times 10^{11}$ & $3.57 \times 10^{10}$ & $9.80 \times 10^{10}$ & 57.67 & 48.84 & 24.53 & 0 & 0 & 0 \\
\hline $4-9$ & $9.60 \times 10^{10}$ & $2.00 \times 10^{10}$ & $5.01 \times 10^{10}$ & 50.61 & 43.57 & 22.16 & 1 & 0 & 1 \\
\hline $4-10$ & $1.17 \times 10^{11}$ & $3.68 \times 10^{10}$ & $1.00 \times 10^{11}$ & 52.44 & 51.01 & 23.35 & 0 & 0 & 0 \\
\hline $5-1$ & $5.98 \times 10^{10}$ & $8.62 \times 10^{09}$ & $2.33 \times 10^{10}$ & 38.79 & 37.86 & 15.26 & 0 & 0 & 0 \\
\hline $5-2$ & $4.97 \times 10^{10}$ & $5.96 \times 10^{09}$ & $3.96 \times 10^{10}$ & 44.22 & 41.56 & 14.65 & 0 & 0 & 0 \\
\hline $5-3$ & $4.12 \times 10^{10}$ & $8.46 \times 10^{09}$ & $2.96 \times 10^{10}$ & 48.80 & 42.69 & 12.97 & 1 & 1 & 2 \\
\hline $5-4$ & $5.03 \times 10^{10}$ & $5.82 \times 10^{09}$ & $2.86 \times 10^{10}$ & 48.09 & 41.53 & 12.83 & 0 & 0 & 0 \\
\hline $5-5$ & $6.91 \times 10^{10}$ & $6.65 \times 10^{09}$ & $3.20 \times 10^{10}$ & 52.41 & 46.81 & 11.64 & 1 & 0 & 1 \\
\hline $5-6$ & $4.22 \times 10^{10}$ & $1.10 \times 10^{10}$ & $1.77 \times 10^{10}$ & 45.21 & 33.01 & 10.85 & 0 & 0 & 0 \\
\hline $5-7$ & $4.71 \times 10^{10}$ & $8.99 \times 10^{09}$ & $3.09 \times 10^{10}$ & 50.63 & 41.21 & 16.26 & 0 & 0 & 0 \\
\hline $5-8$ & $3.90 \times 10^{10}$ & $1.99 \times 10^{10}$ & $1.95 \times 10^{10}$ & 45.92 & 34.53 & 13.95 & 0 & 1 & 1 \\
\hline $5-9$ & $6.28 \times 10^{10}$ & $1.30 \times 10^{10}$ & $3.14 \times 10^{10}$ & 53.99 & 48.13 & 16.97 & 1 & 0 & 1 \\
\hline
\end{tabular}


Table 1. Cont.

\begin{tabular}{|c|c|c|c|c|c|c|c|c|c|}
\hline Run & $(\mathrm{dP1} / \mathrm{dt})^{2} \mathrm{Max}$ & $(\mathrm{dP} 2 / \mathrm{dt})^{2} \mathrm{Max}$ & $(\mathrm{dP} 3 / \mathrm{dt})^{2} \mathrm{Max}$ & $\mathbf{P} 1_{\max }$ & $\mathbf{P} 2_{\max }$ & $\mathbf{P} 3_{\max }$ & Left Reject & $\begin{array}{l}\text { Right } \\
\text { Reject }\end{array}$ & $\begin{array}{c}\text { Total } \\
\text { Reject }\end{array}$ \\
\hline $5-10$ & $4.63 \times 10^{10}$ & $6.36 \times 10^{09}$ & $2.80 \times 10^{10}$ & 45.43 & 38.76 & 8.90 & 0 & 1 & 1 \\
\hline $6-1$ & $2.13 \times 10^{11}$ & $4.16 \times 10^{10}$ & $1.20 \times 10^{11}$ & 61.92 & 48.44 & 24.76 & 1 & 1 & 2 \\
\hline $6-2$ & $2.06 \times 10^{11}$ & $5.53 \times 10^{10}$ & $1.43 \times 10^{11}$ & 59.85 & 51.18 & 26.45 & 0 & 0 & 0 \\
\hline $6-3$ & $1.93 \times 10^{11}$ & $3.66 \times 10^{10}$ & $1.39 \times 10^{11}$ & 61.77 & 50.25 & 23.57 & 1 & 1 & 2 \\
\hline $6-4$ & $1.89 \times 10^{11}$ & $8.00 \times 10^{10}$ & $1.15 \times 10^{11}$ & 61.91 & 41.45 & 30.54 & 1 & 1 & 2 \\
\hline $6-5$ & $2.19 \times 10^{11}$ & $7.89 \times 10^{10}$ & $1.43 \times 10^{11}$ & 64.14 & 50.25 & 31.16 & 1 & 0 & 1 \\
\hline $6-6$ & $2.85 \times 10^{11}$ & $6.99 \times 10^{10}$ & $1.55 \times 10^{11}$ & 68.74 & 53.89 & 30.78 & 1 & 0 & 1 \\
\hline $6-7$ & $2.28 \times 10^{11}$ & $6.76 \times 10^{10}$ & $1.66 \times 10^{11}$ & 67.04 & 55.50 & 33.21 & 1 & 0 & 1 \\
\hline $6-8$ & $2.31 \times 10^{11}$ & $5.37 \times 10^{10}$ & $1.55 \times 10^{11}$ & 65.00 & 51.99 & 27.82 & 1 & 0 & 1 \\
\hline $6-9$ & $2.38 \times 10^{11}$ & $7.37 \times 10^{10}$ & $1.65 \times 10^{11}$ & 68.21 & 54.82 & 29.60 & 1 & 0 & 1 \\
\hline $6-10$ & $2.13 \times 10^{11}$ & $8.31 \times 10^{10}$ & $1.41 \times 10^{11}$ & 62.90 & 49.42 & 30.70 & 0 & 1 & 1 \\
\hline $7-1$ & $2.53 \times 10^{11}$ & $7.01 \times 10^{10}$ & $1.47 \times 10^{11}$ & 69.20 & 54.84 & 34.33 & 0 & 0 & 0 \\
\hline $7-2$ & $1.13 \times 10^{11}$ & $2.92 \times 10^{10}$ & $8.00 \times 10^{10}$ & 65.15 & 54.67 & 31.47 & 1 & 0 & 1 \\
\hline $7-3$ & $1.13 \times 10^{11}$ & $2.92 \times 10^{10}$ & $8.00 \times 10^{10}$ & 65.15 & 54.67 & 31.47 & 1 & 0 & 1 \\
\hline $7-4$ & $1.98 \times 10^{11}$ & $5.43 \times 10^{10}$ & $1.58 \times 10^{11}$ & 60.78 & 48.35 & 26.67 & 1 & 0 & 1 \\
\hline $7-5$ & $1.98 \times 10^{11}$ & $5.43 \times 10^{10}$ & $1.58 \times 10^{11}$ & 60.78 & 48.35 & 26.67 & 0 & 1 & 1 \\
\hline $7-6$ & $2.22 \times 10^{11}$ & $5.21 \times 10^{10}$ & $1.31 \times 10^{11}$ & 66.06 & 45.67 & 26.79 & 0 & 0 & 0 \\
\hline $7-7$ & $2.32 \times 10^{11}$ & $9.21 \times 10^{10}$ & $1.44 \times 10^{11}$ & 66.82 & 46.08 & 32.95 & 0 & 0 & 0 \\
\hline $7-8$ & $2.31 \times 10^{11}$ & $6.92 \times 10^{10}$ & $1.53 \times 10^{11}$ & 67.39 & 50.80 & 29.03 & 1 & 0 & 1 \\
\hline $7-9$ & $2.80 \times 10^{11}$ & $5.78 \times 10^{10}$ & $1.48 \times 10^{11}$ & 71.21 & 56.05 & 28.24 & 1 & 0 & 1 \\
\hline $7-10$ & $2.75 \times 10^{11}$ & $6.63 \times 10^{10}$ & $1.47 \times 10^{11}$ & 70.50 & 51.08 & 29.30 & 1 & 0 & 1 \\
\hline $8-1$ & $3.49 \times 10^{10}$ & $9.62 \times 10^{09}$ & $2.88 \times 10^{10}$ & 56.51 & 40.74 & 15.07 & 1 & 0 & 1 \\
\hline $8-2$ & $3.42 \times 10^{10}$ & $9.62 \times 10^{09}$ & $3.05 \times 10^{10}$ & 63.82 & 45.65 & 16.72 & 1 & 0 & 1 \\
\hline $8-3$ & $4.06 \times 10^{10}$ & $1.20 \times 10^{10}$ & $3.06 \times 10^{10}$ & 64.38 & 46.30 & 18.82 & 1 & 0 & 1 \\
\hline $8-4$ & $3.63 \times 10^{10}$ & $7.17 \times 10^{09}$ & $3.20 \times 10^{10}$ & 61.35 & 44.99 & 16.62 & 1 & 0 & 1 \\
\hline $8-5$ & $4.30 \times 10^{10}$ & $3.43 \times 10^{09}$ & $3.11 \times 10^{10}$ & 58.58 & 44.43 & 10.77 & 0 & 0 & 0 \\
\hline $8-6$ & $4.61 \times 10^{10}$ & $1.27 \times 10^{10}$ & $2.71 \times 10^{10}$ & 63.91 & 49.58 & 24.99 & 0 & 1 & 1 \\
\hline $8-7$ & $4.91 \times 10^{10}$ & $1.18 \times 10^{10}$ & $2.88 \times 10^{10}$ & 65.55 & 48.48 & 22.40 & 0 & 0 & 0 \\
\hline $8-8$ & $6.23 \times 10^{10}$ & $1.27 \times 10^{10}$ & $4.20 \times 10^{10}$ & 65.01 & 51.06 & 18.00 & 0 & 0 & 0 \\
\hline $8-9$ & $5.15 \times 10^{10}$ & $8.21 \times 10^{09}$ & $3.51 \times 10^{10}$ & 61.45 & 46.94 & 15.29 & 1 & 1 & 2 \\
\hline $8-10$ & $4.36 \times 10^{10}$ & $1.02 \times 10^{10}$ & $2.85 \times 10^{10}$ & 61.43 & 50.06 & 21.29 & 0 & 0 & 0 \\
\hline $9-1$ & $3.33 \times 10^{10}$ & $2.52 \times 10^{10}$ & $4.07 \times 10^{10}$ & 50.45 & 45.66 & 16.96 & 1 & 1 & 2 \\
\hline $9-2$ & $1.57 \times 10^{11}$ & $1.97 \times 10^{10}$ & $8.75 \times 10^{10}$ & 55.00 & 44.11 & 20.43 & 0 & 0 & 0 \\
\hline $9-3$ & $1.82 \times 10^{11}$ & $4.70 \times 10^{10}$ & $1.18 \times 10^{11}$ & 58.15 & 47.26 & 25.99 & 0 & 0 & 0 \\
\hline $9-4$ & $1.39 \times 10^{11}$ & $2.33 \times 10^{10}$ & $9.56 \times 10^{10}$ & 61.30 & 49.47 & 22.66 & 1 & 0 & 1 \\
\hline $9-5$ & $1.60 \times 10^{11}$ & $1.31 \times 10^{11}$ & $9.20 \times 10^{10}$ & 60.30 & 46.39 & 36.83 & 0 & 0 & 0 \\
\hline $9-6$ & $1.60 \times 10^{11}$ & $1.31 \times 10^{11}$ & $9.20 \times 10^{10}$ & 60.30 & 46.39 & 36.83 & 0 & 0 & 0 \\
\hline $9-7$ & $1.81 \times 10^{11}$ & $2.77 \times 10^{10}$ & $1.20 \times 10^{11}$ & 61.33 & 50.91 & 23.82 & 1 & 0 & 1 \\
\hline $9-8$ & $1.99 \times 10^{11}$ & $5.60 \times 10^{10}$ & $1.17 \times 10^{11}$ & 60.79 & 49.39 & 28.08 & 1 & 1 & 2 \\
\hline $9-9$ & $2.07 \times 10^{11}$ & $4.55 \times 10^{10}$ & $1.28 \times 10^{11}$ & 60.63 & 41.12 & 25.50 & 1 & 0 & 1 \\
\hline $9-10$ & $5.57 \times 10^{10}$ & $1.76 \times 10^{10}$ & $1.66 \times 10^{10}$ & 46.50 & 30.93 & 14.10 & 0 & 1 & 1 \\
\hline $10-1$ & $3.98 \times 10^{10}$ & $1.44 \times 10^{10}$ & $3.20 \times 10^{10}$ & 53.36 & 46.17 & 21.49 & 1 & 1 & 2 \\
\hline $10-2$ & $3.73 \times 10^{10}$ & $5.89 \times 10^{09}$ & $3.25 \times 10^{10}$ & 56.36 & 44.90 & 14.44 & 0 & 0 & 0 \\
\hline $10-3$ & $3.55 \times 10^{10}$ & $3.12 \times 10^{09}$ & $3.06 \times 10^{10}$ & 53.69 & 46.63 & 8.15 & 0 & 0 & 0 \\
\hline $10-4$ & $4.04 \times 10^{10}$ & $2.67 \times 10^{10}$ & $3.28 \times 10^{10}$ & 49.62 & 43.03 & 19.53 & 0 & 1 & 1 \\
\hline $10-5$ & $3.99 \times 10^{10}$ & $4.89 \times 10^{09}$ & $3.30 \times 10^{10}$ & 53.63 & 47.79 & 15.04 & 0 & 0 & 0 \\
\hline $10-6$ & $3.48 \times 10^{10}$ & $8.51 \times 10^{09}$ & $2.74 \times 10^{10}$ & 56.68 & 49.40 & 15.77 & 0 & 0 & 0 \\
\hline $10-7$ & $3.61 \times 10^{10}$ & $1.05 \times 10^{10}$ & $2.70 \times 10^{10}$ & 55.39 & 48.24 & 19.37 & 1 & 0 & 1 \\
\hline $10-8$ & $3.61 \times 10^{10}$ & $7.32 \times 10^{09}$ & $3.50 \times 10^{10}$ & 55.07 & 50.61 & 16.74 & 1 & 0 & 1 \\
\hline $10-9$ & $3.61 \times 10^{10}$ & $7.32 \times 10^{09}$ & $3.50 \times 10^{10}$ & 55.07 & 50.61 & 16.74 & 0 & 0 & 0 \\
\hline $10-10$ & $3.45 \times 10^{10}$ & $9.21 \times 10^{09}$ & $2.97 \times 10^{10}$ & 49.25 & 50.19 & 20.31 & 0 & 1 & 1 \\
\hline $11-1$ & $3.41 \times 10^{10}$ & $1.15 \times 10^{10}$ & $2.68 \times 10^{10}$ & 52.39 & 51.51 & 21.87 & 0 & 1 & 1 \\
\hline $11-2$ & $3.09 \times 10^{10}$ & $1.02 \times 10^{10}$ & $2.72 \times 10^{10}$ & 47.21 & 49.54 & 19.38 & 0 & 0 & 0 \\
\hline $11-3$ & $4.37 \times 10^{10}$ & $8.59 \times 10^{09}$ & $2.91 \times 10^{10}$ & 38.53 & 50.00 & 22.77 & 0 & 0 & 0 \\
\hline $11-4$ & $5.21 \times 10^{10}$ & $8.54 \times 10^{09}$ & $2.81 \times 10^{10}$ & 34.99 & 49.53 & 21.98 & 1 & 0 & 1 \\
\hline $11-5$ & $3.20 \times 10^{10}$ & $6.33 \times 10^{09}$ & $2.60 \times 10^{10}$ & 31.00 & 49.53 & 14.88 & 0 & 0 & 0 \\
\hline $11-6$ & $2.49 \times 10^{09}$ & $6.62 \times 10^{09}$ & $2.17 \times 10^{10}$ & 3.36 & 44.40 & 18.13 & 1 & 0 & 1 \\
\hline $11-7$ & $4.30 \times 10^{09}$ & $9.65 \times 10^{09}$ & $2.47 \times 10^{10}$ & 3.36 & 48.81 & 19.34 & 0 & 0 & 0 \\
\hline $11-8$ & $1.30 \times 10^{09}$ & $6.31 \times 10^{09}$ & $2.66 \times 10^{10}$ & 3.16 & 48.62 & 13.87 & 0 & 0 & 0 \\
\hline $11-9$ & $2.99 \times 10^{09}$ & $8.73 \times 10^{09}$ & $2.49 \times 10^{10}$ & 3.57 & 51.93 & 19.14 & 0 & 0 & 0 \\
\hline $11-10$ & $2.16 \times 10^{09}$ & $2.90 \times 10^{09}$ & $2.72 \times 10^{10}$ & 3.25 & 48.81 & 12.13 & 0 & 0 & 0 \\
\hline $12-1$ & $2.40 \times 10^{09}$ & $6.14 \times 10^{10}$ & $1.37 \times 10^{11}$ & 3.31 & 50.44 & 27.85 & 0 & 0 & 0 \\
\hline $12-2$ & $2.15 \times 10^{09}$ & $8.50 \times 10^{10}$ & $1.26 \times 10^{11}$ & 3.32 & 43.62 & 32.09 & 0 & & 0 \\
\hline $12-3$ & $2.66 \times 10^{09}$ & $1.03 \times 10^{11}$ & $1.59 \times 10^{11}$ & 3.21 & 51.54 & 33.70 & 1 & 0 & 1 \\
\hline
\end{tabular}


Table 1. Cont.

\begin{tabular}{|c|c|c|c|c|c|c|c|c|c|}
\hline Run & $(\mathrm{dP} 1 / \mathrm{dt})^{2} \operatorname{Max}$ & $(\mathrm{dP} 2 / \mathrm{dt})^{2} \operatorname{Max}$ & $(\mathrm{dP} 3 / \mathrm{dt})^{2} \operatorname{Max}$ & $\mathbf{P} 1_{\max }$ & $\mathbf{P} 2_{\max }$ & $P 3_{\max }$ & Left Reject & $\begin{array}{l}\text { Right } \\
\text { Reject }\end{array}$ & $\begin{array}{c}\text { Total } \\
\text { Reject }\end{array}$ \\
\hline $12-4$ & $1.83 \times 10^{09}$ & $9.97 \times 10^{10}$ & $1.68 \times 10^{11}$ & 3.10 & 50.83 & 34.32 & 0 & 0 & 0 \\
\hline $12-5$ & $1.12 \times 10^{09}$ & $6.71 \times 10^{10}$ & $1.14 \times 10^{11}$ & 3.20 & 49.89 & 29.05 & 0 & 1 & 1 \\
\hline $12-6$ & $2.23 \times 10^{09}$ & $2.75 \times 10^{10}$ & $4.32 \times 10^{10}$ & 3.16 & 36.42 & 19.07 & 0 & 0 & 0 \\
\hline $12-7$ & $1.23 \times 10^{09}$ & $2.19 \times 10^{09}$ & $9.29 \times 10^{10}$ & 3.24 & 43.27 & 3.98 & 0 & 0 & 0 \\
\hline $12-8$ & $1.96 \times 10^{09}$ & $3.50 \times 10^{10}$ & $1.10 \times 10^{11}$ & 3.08 & 51.20 & 24.79 & 0 & 0 & 0 \\
\hline $12-9$ & $2.63 \times 10^{09}$ & $3.79 \times 10^{10}$ & $1.09 \times 10^{11}$ & 3.10 & 51.15 & 25.56 & 1 & 0 & 1 \\
\hline $12-10$ & $2.74 \times 10^{09}$ & $8.80 \times 10^{10}$ & $1.13 \times 10^{11}$ & 3.11 & 39.12 & 31.23 & 0 & 0 & 0 \\
\hline $13-1$ & $3.73 \times 10^{10}$ & $9.25 \times 10^{10}$ & $8.69 \times 10^{10}$ & 27.64 & 38.36 & 30.74 & 1 & 0 & 1 \\
\hline $13-2$ & $6.27 \times 10^{10}$ & $1.49 \times 10^{10}$ & $9.84 \times 10^{10}$ & 36.61 & 45.18 & 18.11 & 1 & 0 & 1 \\
\hline $13-3$ & $4.13 \times 10^{10}$ & $2.53 \times 10^{10}$ & $1.00 \times 10^{11}$ & 30.60 & 46.58 & 20.31 & 0 & 0 & 0 \\
\hline $13-4$ & $3.88 \times 10^{10}$ & $3.31 \times 10^{10}$ & $8.07 \times 10^{10}$ & 31.45 & 45.08 & 20.29 & 0 & 1 & 1 \\
\hline $13-5$ & $5.99 \times 10^{10}$ & $2.05 \times 10^{10}$ & $1.03 \times 10^{11}$ & 38.30 & 48.61 & 20.63 & 1 & 0 & 1 \\
\hline $13-6$ & $5.74 \times 10^{10}$ & $6.06 \times 10^{10}$ & $1.35 \times 10^{11}$ & 37.73 & 51.19 & 27.95 & 0 & 0 & 0 \\
\hline $13-7$ & $7.09 \times 10^{10}$ & $8.30 \times 10^{10}$ & $1.41 \times 10^{11}$ & 42.14 & 45.20 & 30.21 & 0 & 0 & 0 \\
\hline $13-8$ & $7.55 \times 10^{10}$ & $8.34 \times 10^{10}$ & $1.31 \times 10^{11}$ & 42.64 & 44.14 & 28.83 & 1 & 0 & 1 \\
\hline $13-9$ & $7.20 \times 10^{10}$ & $1.15 \times 10^{11}$ & $1.45 \times 10^{11}$ & 38.33 & 46.38 & 33.48 & 1 & 0 & 1 \\
\hline $13-10$ & $5.41 \times 10^{10}$ & $1.02 \times 10^{11}$ & $1.68 \times 10^{11}$ & 42.56 & 51.80 & 32.73 & 0 & 0 & 0 \\
\hline $14-1$ & $3.97 \times 10^{10}$ & $1.54 \times 10^{10}$ & $6.26 \times 10^{10}$ & 46.58 & 44.65 & 16.37 & 0 & 0 & 0 \\
\hline $14-2$ & $1.33 \times 10^{09}$ & $5.92 \times 10^{09}$ & $2.93 \times 10^{10}$ & 3.23 & 37.66 & 9.12 & 1 & 1 & 2 \\
\hline $14-3$ & $3.38 \times 10^{10}$ & $5.67 \times 10^{10}$ & $9.06 \times 10^{10}$ & 26.23 & 43.62 & 26.81 & 1 & 0 & 1 \\
\hline $14-4$ & $3.25 \times 10^{10}$ & $6.70 \times 10^{10}$ & $1.21 \times 10^{11}$ & 26.24 & 51.51 & 29.98 & 1 & 1 & 2 \\
\hline $14-5$ & $3.40 \times 10^{10}$ & $6.21 \times 10^{10}$ & $1.22 \times 10^{11}$ & 24.87 & 48.21 & 28.16 & 1 & 0 & 1 \\
\hline $14-6$ & $3.63 \times 10^{09}$ & $7.55 \times 10^{10}$ & $1.09 \times 10^{11}$ & 3.58 & 43.42 & 29.64 & 1 & 0 & 1 \\
\hline $14-7$ & $5.21 \times 10^{10}$ & $8.54 \times 10^{09}$ & $2.81 \times 10^{10}$ & 34.99 & 49.53 & 21.98 & 1 & 0 & 1 \\
\hline $14-8$ & $1.80 \times 10^{09}$ & $7.70 \times 10^{10}$ & $1.27 \times 10^{11}$ & 3.24 & 46.80 & 29.40 & 1 & 0 & 1 \\
\hline $14-9$ & $2.64 \times 10^{10}$ & $7.02 \times 10^{10}$ & $1.23 \times 10^{11}$ & 22.73 & 49.94 & 30.71 & 0 & 0 & 0 \\
\hline $14-10$ & $2.00 \times 10^{09}$ & $8.49 \times 10^{10}$ & $1.49 \times 10^{11}$ & 3.40 & 49.60 & 30.99 & 1 & 0 & 1 \\
\hline $15-1$ & $1.54 \times 10^{09}$ & $8.21 \times 10^{10}$ & $1.72 \times 10^{11}$ & 3.33 & 48.33 & 30.60 & 1 & 1 & 2 \\
\hline $15-2$ & $1.82 \times 10^{09}$ & $8.26 \times 10^{10}$ & $1.45 \times 10^{11}$ & 3.54 & 49.06 & 30.09 & 0 & 0 & 0 \\
\hline $15-3$ & $3.31 \times 10^{10}$ & $9.85 \times 10^{10}$ & $1.32 \times 10^{11}$ & 29.65 & 46.49 & 33.57 & 0 & 0 & 0 \\
\hline $15-4$ & $9.44 \times 10^{09}$ & $9.10 \times 10^{10}$ & $1.50 \times 10^{11}$ & 20.79 & 53.45 & 31.89 & 0 & 0 & 0 \\
\hline $15-5$ & $1.32 \times 10^{09}$ & $9.84 \times 10^{10}$ & $1.58 \times 10^{11}$ & 3.19 & 51.39 & 32.81 & 1 & 0 & 1 \\
\hline $15-6$ & $2.18 \times 10^{09}$ & $9.63 \times 10^{10}$ & $1.55 \times 10^{11}$ & 3.41 & 50.34 & 32.47 & 0 & 1 & 1 \\
\hline $15-7$ & $2.01 \times 10^{09}$ & $6.60 \times 10^{10}$ & $1.59 \times 10^{11}$ & 3.21 & 51.29 & 29.15 & 0 & 0 & 0 \\
\hline $15-8$ & $1.73 \times 10^{09}$ & $1.02 \times 10^{11}$ & $1.62 \times 10^{11}$ & 3.22 & 52.57 & 34.51 & 0 & 0 & 0 \\
\hline $15-9$ & $1.99 \times 10^{09}$ & $9.16 \times 10^{10}$ & $1.58 \times 10^{11}$ & 3.57 & 55.31 & 35.17 & 0 & 0 & 0 \\
\hline $15-10$ & $2.30 \times 10^{09}$ & $9.92 \times 10^{10}$ & $1.44 \times 10^{11}$ & 3.37 & 47.51 & 33.19 & 0 & 0 & 0 \\
\hline $16-1$ & $2.06 \times 10^{10}$ & $5.85 \times 10^{09}$ & $2.20 \times 10^{10}$ & 26.26 & 29.50 & 11.40 & 1 & 1 & 2 \\
\hline $16-2$ & $1.36 \times 10^{10}$ & $2.51 \times 10^{10}$ & $1.89 \times 10^{10}$ & 18.86 & 23.67 & 20.13 & 1 & 0 & 1 \\
\hline $16-3$ & $7.84 \times 10^{09}$ & $1.62 \times 10^{10}$ & $1.98 \times 10^{10}$ & 24.84 & 36.35 & 15.44 & 1 & 0 & 1 \\
\hline $16-4$ & $2.25 \times 10^{09}$ & $1.86 \times 10^{10}$ & $3.19 \times 10^{10}$ & 3.42 & 41.59 & 15.58 & 1 & 0 & 1 \\
\hline $16-5$ & $2.17 \times 10^{11}$ & $1.01 \times 10^{11}$ & $1.90 \times 10^{11}$ & 62.19 & 55.63 & 34.18 & 0 & 0 & 0 \\
\hline $16-6$ & $3.34 \times 10^{09}$ & $4.74 \times 10^{09}$ & $2.05 \times 10^{10}$ & 3.57 & 43.60 & 14.30 & 1 & 0 & 1 \\
\hline $16-7$ & $2.86 \times 10^{09}$ & $2.47 \times 10^{10}$ & $2.53 \times 10^{10}$ & 3.53 & 40.46 & 28.18 & 1 & 0 & 1 \\
\hline $16-8$ & $1.72 \times 10^{09}$ & $6.17 \times 10^{09}$ & $2.63 \times 10^{10}$ & 3.36 & 37.21 & 14.16 & 1 & 0 & 1 \\
\hline $16-9$ & $2.54 \times 10^{09}$ & $1.72 \times 10^{10}$ & $2.94 \times 10^{10}$ & 3.34 & 41.93 & 20.38 & 0 & 0 & 0 \\
\hline $16-10$ & $2.58 \times 10^{09}$ & $1.38 \times 10^{10}$ & $2.29 \times 10^{10}$ & 3.38 & 41.64 & 13.58 & 1 & 1 & 2 \\
\hline $17-1$ & $2.67 \times 10^{10}$ & $2.25 \times 10^{09}$ & $2.97 \times 10^{10}$ & 22.69 & 41.61 & 5.95 & 0 & 0 & 0 \\
\hline $17-2$ & $2.48 \times 10^{09}$ & $2.39 \times 10^{09}$ & $1.58 \times 10^{10}$ & 3.17 & 21.04 & 5.44 & 1 & 1 & 2 \\
\hline $17-3$ & $2.82 \times 10^{09}$ & $1.03 \times 10^{10}$ & $5.96 \times 10^{09}$ & 3.30 & 8.08 & 11.70 & 1 & 1 & 2 \\
\hline $17-4$ & $5.14 \times 10^{09}$ & $2.86 \times 10^{10}$ & $5.67 \times 10^{10}$ & 10.96 & 23.75 & 14.21 & 1 & 1 & 2 \\
\hline $17-5$ & $2.15 \times 10^{09}$ & $5.58 \times 10^{09}$ & $2.74 \times 10^{09}$ & 3.35 & 2.59 & 10.04 & 0 & 1 & 1 \\
\hline $17-6$ & $2.48 \times 10^{09}$ & $1.88 \times 10^{09}$ & $4.07 \times 10^{09}$ & 3.21 & 2.59 & 2.51 & 1 & 1 & 2 \\
\hline $17-7$ & $1.89 \times 10^{10}$ & $5.69 \times 10^{09}$ & $2.28 \times 10^{10}$ & 19.15 & 31.39 & 10.96 & 1 & 0 & 1 \\
\hline $17-8$ & $3.02 \times 10^{09}$ & $4.52 \times 10^{09}$ & $1.09 \times 10^{10}$ & 3.47 & 27.53 & 7.74 & 1 & 0 & 1 \\
\hline $17-9$ & $2.97 \times 10^{10}$ & $8.96 \times 10^{09}$ & $1.76 \times 10^{10}$ & 23.34 & 30.70 & 8.81 & 0 & 0 & 0 \\
\hline $17-10$ & $3.30 \times 10^{10}$ & $5.96 \times 10^{09}$ & $2.60 \times 10^{10}$ & 25.95 & 33.67 & 14.59 & 0 & 0 & 0 \\
\hline $18-1$ & $1.89 \times 10^{09}$ & $8.54 \times 10^{09}$ & $4.52 \times 10^{09}$ & 3.00 & 2.69 & 14.16 & 1 & 0 & 1 \\
\hline $18-2$ & $1.68 \times 10^{09}$ & $5.64 \times 10^{09}$ & $3.84 \times 10^{10}$ & 3.06 & 33.06 & 8.88 & 1 & 1 & 2 \\
\hline $18-3$ & $4.21 \times 1010$ & $8.32 \times 10^{09}$ & $6.20 \times 10^{10}$ & 28.00 & 32.53 & 14.97 & 0 & 0 & 0 \\
\hline $18-4$ & $2.36 \times 10^{10}$ & $1.43 \times 10^{10}$ & $3.12 \times 10^{10}$ & 23.08 & 27.31 & 17.24 & 0 & 0 & 0 \\
\hline $18-5$ & $2.52 \times 10^{10}$ & $2.52 \times 10^{09}$ & $4.47 \times 10^{10}$ & 25.35 & 38.14 & 5.96 & 0 & 1 & 1 \\
\hline $18-6$ & $3.59 \times 10^{10}$ & $3.19 \times 10^{10}$ & $3.56 \times 10^{10}$ & 31.35 & 29.11 & 19.51 & 0 & 0 & 0 \\
\hline $18-7$ & $2.67 \times 10^{10}$ & $4.12 \times 10^{10}$ & $4.24 \times 10^{10}$ & 25.19 & 30.30 & 21.33 & 0 & 1 & 1 \\
\hline
\end{tabular}


Table 1. Cont.

\begin{tabular}{|c|c|c|c|c|c|c|c|c|c|}
\hline Run & $(\mathrm{dP1} / \mathrm{dt})^{2} \mathrm{Max}$ & $(\mathrm{dP} 2 / \mathrm{dt})^{2} \mathrm{Max}$ & $(\mathrm{dP} 3 / \mathrm{dt})^{2} \mathrm{Max}$ & $\mathbf{P} 1_{\max }$ & $\mathbf{P} 2_{\max }$ & $\mathbf{P} 3_{\max }$ & Left Reject & $\begin{array}{l}\text { Right } \\
\text { Reject }\end{array}$ & $\begin{array}{c}\text { Total } \\
\text { Reject }\end{array}$ \\
\hline $18-8$ & $1.11 \times 10^{10}$ & $1.86 \times 10^{10}$ & $3.28 \times 10^{09}$ & 21.66 & 4.71 & 12.97 & 0 & 1 & 1 \\
\hline $18-9$ & $2.74 \times 10^{10}$ & $1.34 \times 10^{10}$ & $2.53 \times 10^{10}$ & 24.51 & 17.50 & 13.60 & 1 & 1 & 2 \\
\hline $18-10$ & $6.84 \times 10^{10}$ & $8.55 \times 10^{10}$ & $4.87 \times 10^{10}$ & 32.89 & 29.74 & 30.66 & 0 & 0 & 0 \\
\hline $19-1$ & $2.94 \times 10^{10}$ & $1.52 \times 10^{10}$ & $3.87 \times 10^{10}$ & 35.22 & 27.99 & 12.08 & 1 & 0 & 1 \\
\hline $19-2$ & $2.97 \times 10^{10}$ & $7.09 \times 10^{09}$ & $2.80 \times 10^{10}$ & 37.43 & 42.13 & 15.46 & 0 & 1 & 1 \\
\hline $19-3$ & $3.09 \times 10^{10}$ & $1.02 \times 10^{10}$ & $3.11 \times 10^{10}$ & 37.93 & 35.43 & 9.89 & 0 & 1 & 1 \\
\hline $19-4$ & $2.68 \times 10^{10}$ & $8.29 \times 10^{09}$ & $4.52 \times 10^{10}$ & 37.51 & 27.77 & 9.23 & 1 & 0 & 1 \\
\hline $19-5$ & $3.88 \times 10^{10}$ & $1.02 \times 10^{10}$ & $3.87 \times 10^{10}$ & 45.18 & 45.01 & 11.42 & 0 & 1 & 1 \\
\hline $19-6$ & $6.34 \times 10^{10}$ & $2.35 \times 10^{10}$ & $4.30 \times 10^{10}$ & 41.04 & 41.51 & 20.31 & 0 & 0 & 0 \\
\hline $19-7$ & $6.34 \times 10^{10}$ & $2.35 \times 10^{10}$ & $4.30 \times 10^{10}$ & 41.04 & 41.51 & 20.31 & 1 & 0 & 1 \\
\hline $19-8$ & $3.92 \times 10^{10}$ & $7.47 \times 10^{09}$ & $3.12 \times 10^{10}$ & 39.93 & 35.90 & 14.21 & 0 & 0 & 0 \\
\hline $19-9$ & $3.75 \times 10^{10}$ & $7.45 \times 10^{09}$ & $2.50 \times 10^{10}$ & 42.39 & 40.87 & 15.73 & 1 & 0 & 1 \\
\hline $19-10$ & $3.75 \times 10^{10}$ & $7.45 \times 10^{09}$ & $2.50 \times 10^{10}$ & 42.39 & 40.87 & 15.73 & 0 & 1 & 1 \\
\hline $20-1$ & $7.99 \times 10^{10}$ & $4.50 \times 10^{10}$ & $1.07 \times 10^{11}$ & 43.94 & 48.81 & 24.65 & 0 & 0 & 0 \\
\hline $20-2$ & $9.99 \times 10^{10}$ & $7.34 \times 10^{10}$ & $9.13 \times 10^{10}$ & 46.23 & 40.23 & 27.79 & 1 & 0 & 1 \\
\hline $20-3$ & $9.05 \times 10^{10}$ & $1.08 \times 10^{10}$ & $5.32 \times 10^{10}$ & 45.07 & 40.67 & 16.09 & 0 & 1 & 1 \\
\hline $20-4$ & $5.30 \times 10^{10}$ & $2.74 \times 10^{09}$ & $4.31 \times 10^{10}$ & 43.10 & 29.80 & 5.94 & 0 & 0 & 0 \\
\hline $20-5$ & $7.17 \times 10^{10}$ & $7.38 \times 10^{10}$ & $1.27 \times 10^{11}$ & 40.57 & 48.05 & 29.79 & 0 & 0 & 0 \\
\hline $20-6$ & $8.56 \times 10^{10}$ & $3.68 \times 10^{09}$ & $8.62 \times 10^{10}$ & 41.50 & 47.20 & 6.69 & 0 & 0 & 0 \\
\hline $20-7$ & $5.97 \times 10^{10}$ & $2.42 \times 10^{10}$ & $8.05 \times 10^{10}$ & 33.89 & 48.49 & 22.65 & 0 & 0 & 0 \\
\hline $20-8$ & $8.90 \times 10^{10}$ & $8.08 \times 10^{09}$ & $1.14 \times 10^{11}$ & 46.63 & 41.69 & 9.18 & 0 & 1 & 1 \\
\hline $20-9$ & $1.02 \times 10^{11}$ & $6.57 \times 10^{10}$ & $1.11 \times 10^{11}$ & 43.12 & 41.53 & 27.83 & 1 & 0 & 1 \\
\hline $20-10$ & $4.79 \times 10^{10}$ & $9.47 \times 10^{10}$ & $1.12 \times 10^{11}$ & 29.77 & 42.40 & 30.58 & 0 & 0 & 0 \\
\hline
\end{tabular}

\section{References}

1. Ghomashchi, M.R.; Vikhrov, A. Squeeze Casting: An Overview. J. Mater. Process. Technol. 2000, 101, 1-9. [CrossRef]

2. Jarfors, A.E.W. Pressure Different Casting. In Encyclopedia of Materials: Metals and Allloys; Elsevier: Amsterdam, The Netherlands, 2022; Volume 4, pp. 117-128.

3. Fiorese, E.; Richiedei, D.; Bonollo, F. Improving the Quality of Die Castings through Optimal Plunger Motion Planning: Analytical Computation and Experimental Validation. Int. J. Adv. Manuf. Technol. 2017, 88, 1475-1484. [CrossRef]

4. Cao, Y.; Guo, Z.; Xiong, S. Determination of the Metal/Die Interfacial Heat Transfer Coefficient of High Pressure Die Cast B390 Alloy. IOP Conf. Series Mater. Sci. Eng. 2012, 33, 012010. [CrossRef]

5. Wang, F.F.; Wu, K.Y.; Wang, X.Y.; Han, Z.Q. Measurement of Temperature inside Die and Estimation of Interfacial Heat Transfer Coefficient in Squeeze Casting. China Foundry 2017, 14, 327-332. [CrossRef]

6. Griffiths, W.D.; Kawai, K. The Effect of Increased Pressure on Interfacial Heat Transfer in the Aluminium Gravity Die Casting Process. J. Mater. Sci. 2010, 45, 2330-2339. [CrossRef]

7. Hamasaiid, A.; Dour, G.; Dargusch, M.S.; Loulou, T.; Davidson, C.; Savage, G. Heat-Transfer Coefficient and in-Cavity Pressure at the Casting-Die Interface during High-Pressure Die Casting of the Magnesium Alloy AZ91D. Metall. Mater. Trans. A 2008, 39, 853-864. [CrossRef]

8. Goh, C.S.; Soh, K.S.; Oon, P.H.; Chua, B.W. Effect of Squeeze Casting Parameters on the Mechanical Properties of AZ91-Ca Mg Alloys. Mater. Des. 2010, 31, S50-S53. [CrossRef]

9. Chang, Q.M.; Chen, C.J.; Zhang, S.C.; Schwam, D.; Wallace, J.F. Effects of Process Parameters on Quality of Squeeze Casting A356 Alloy. Int. J. Cast Met. Res. 2010, 23, 30-36. [CrossRef]

10. Xu, C.L.; Ying, F.Q. Research on Numerical Simulation of Filling Velocity of Indirect Squeeze Casting in Shaping the Thin Walled Workpiece. Appl. Mech. Mater. 2011, 48-49, 964-970. [CrossRef]

11. Campbell, J. Complete Casting Handbook: Metal Casting Processes, Metallurgy, Techniques and Design, 2nd ed.; ButterworthHeinemann: Oxford, UK, 2015; ISBN 978-0-444-63509-9.

12. Jarfors, A.E.W.; Seifeddine, S. Metal Casting. In Handbook of Manufacturing Engineering and Technology; Nee, A.Y.C., Ed.; Springer: London, UK, 2015; ISBN 9781447146704 | 9781447146698.

13. Panicker, P.G.; Kuriakose, S. Parameter Optimisation of Squeeze Casting Process Using LM 20 Alloy: Numeral Analysis by Neural Network and Modified Coefficient-Based Deer Hunting Optimization. Aust. J. Mech. Eng. 2020, 1-17. [CrossRef]

14. Dargusch, M.S.; Dour, G.; Schauer, N.; Dinnis, C.M.; Savage, G. The Influence of Pressure during Solidification of High Pressure Die Cast Aluminium Telecommunications Components. J. Mater. Process. Technol. 2006, 180, 37-43. [CrossRef]

15. Bird, R.B.; Stewart, W.E.; Lightfoot, E.N. Transport Phenomena, 2nd ed.; John Wiley \& Sons, Inc.: New York, NY, USA, 2002; ISBN 0-471-41077-2. 